Article

\title{
Green Synthesis of Free Standing Cellulose/Graphene Oxide/Polyaniline Aerogel Electrode for High-Performance Flexible All-Solid-State Supercapacitors
}

\author{
Yueqin $\mathrm{Li}^{1,2, *(\mathbb{D})}$, Zongbiao Xia ${ }^{1,2}$, Qiang Gong ${ }^{1,2}$, Xiaohui Liu ${ }^{1,2}$, Yong Yang ${ }^{1,2}$, Chen Chen ${ }^{2}$ \\ and Changhao Qian ${ }^{2}$ \\ 1 Co-Innovation Center of Efficient Processing and Utilization of Forest Resources, Nanjing Forestry \\ University, Nanjing 210037, China; zongbiaoxia@163.com (Z.X.); qianggong@163.com (Q.G.); \\ xiaohuiliu@163.com (X.L.); yongyang06@163.com (Y.Y.) \\ 2 College of Chemical Engineering, Jiangsu Key Lab for the Chemistry and Utilization of Agricultural and \\ Forest Biomass, Nanjing Forestry University, Nanjing 210037, China; chenchen@163.com (C.C.); \\ changhaoqian@163.com (C.Q.) \\ * Correspondence: yueqinli@njfu.edu.cn; Tel.: +86-025-85427024
}

Received: 18 July 2020; Accepted: 3 August 2020; Published: 7 August 2020

\begin{abstract}
The cellulose/graphene oxide (GO) networks as the scaffold of free-standing aerogel electrodes are developed by using lithium bromide aqueous solution, as the solvent, to ensure the complete dissolution of cotton linter pulp and well dispersion/reduction of GO nanosheets. Polyaniline (PANI) nanoclusters are then coated onto cellulose/GO networks via in-situ polymerization of aniline monomers. By optimized weight ratio of GO and PANI, the ternary cellulose/GO ${ }_{3.5} / \mathrm{PANI}$ aerogel film exhibits well-defined three-dimensional porous structures and high conductivity of $1.15 \mathrm{~S} / \mathrm{cm}$, which contributes to its high areal specific capacitance of $1218 \mathrm{mF} / \mathrm{cm}^{2}$ at the current density of $1.0 \mathrm{~mA} / \mathrm{cm}^{2}$. Utilizing this cellulose/ $\mathrm{GO}_{3.5} / \mathrm{PANI}$ aerogel film as electrodes in a symmetric configuration supercapacitor can result in an outstanding energy density as high as $258.2 \mu \mathrm{Wh} / \mathrm{cm}^{2}$ at a power density of $1201.4 \mu \mathrm{W} / \mathrm{cm}^{2}$. Moreover, the device can maintain nearly constant capacitance under different bending deformations, suggesting its promising applications in flexible electronics.
\end{abstract}

Keywords: cellulose; graphene oxide; polyaniline; aerogel electrode; supercapacitors

\section{Introduction}

The increasing development of wearable electronic devices has triggered an urgent demand for the adaptive power system to provide sufficient energy for long-term operations. Flexible supercapacitors (SCs), emerging as a promising power source of high-performance electronic devices, have aroused tremendous interest due to their high-power density that can fill the gap between rechargeable batteries and conventional capacitors [1,2]. To obtain high performance for flexible SCs, various flexible electrodes have been constructed by traditional metal oxides, nano-carbons, conductive polymers and their composites [3], as well as new materials comprising two-dimensional Mxenes, polyoxometalates (POMs), metal-organic frameworks (MOFs), etc. [4]. Nevertheless, several factors, including the high cost of raw materials, complex preparing process, and hard mass production are still challenging for practical applications. On the other hand, the appetite for sustainable and biodegradable materials in electronics has been significantly increased as the global warming and energy crisis continue to increase. Recent studies have focused on developing highly flexible, free-standing, and binder-free electrodes using cost-effective and renewable raw polymeric materials [5-7]. In this scenario, commercial cellulose 
products, such as A4 paper, air-laid paper, and Kimwipes, as well as various kinds of nanocellulose (e.g., cellulose nanofibrils (CNFs), cellulose nanocrystals (CNCs), and cellulose nanoyarn (CNY)), have been frequently used as sustainable, flexible and foldable scaffolds as structural matrixes for the conducting fillers in supercapacitors [8-11].

Carbon-based materials (porous carbon, carbon nanotubes (CNTs), graphene, Mexene, etc.) and conducting polymers (polypyrrole (PPy), polyaniline (PANI), poly(3,4-ethylenedioxythiophene): poly(styrene sulfonate) (PEDOT:PSS)) are the most studied and promising electrode materials $[12,13]$. Nevertheless, the prior researches have proved that the single-component of the carbon-based materials or conducting polymers as electrode materials were not satisfied enough to meet the real application due to the substandard energy density in supercapacitors. Thus, the rational design of hierarchical and porous hybrids is still important for the improvement of electrochemical performances of supercapacitors. In general, cellulose-based substrates are combined with conductive polymers, including polypyrrole (PPy) and PANI, by in-situ polymerization in monomer solutions [14-16]. The addition of the extra CNTs or a graphene component makes the preparation more complex, mainly through the "vacuum filtration" strategy or the in-situ culture on bacterial cellulose (BC) [17-20]. For example, $\mathrm{Xu}$ et al. fabricated the PANI/graphene/BC film for supercapacitor electrodes via pouring PANI/GO nanocomposites into BC paper under vacuum [18]. BC/graphene/PANI electrodes were produced by in-situ culture and polymerization [19]. In another study, Dong et al. deposited CNTs on cellulose paper by a "dipping and drying method", followed by in-situ chemical polymerization of aniline monomers, to get stacked up layers in composite networks [21]. Nevertheless, the filtration of CNTs or graphene into the inner core of cellulose paper could not ensure uniform distribution of conducting fillers in the polymeric matrix. In addition, dip-coating in the solution of CNTs or graphene is challenging due to the limited loading of active materials on the film-like sample, resulting in a small areal capacitance of the whole electrodes.

Very recently, aerogel-based electrodes have shown promising applications in supercapacitors, since their high specific surface area and well inter-connected three-dimensional (3D) texture can load a high content of active materials [22-24]. The cellulose/carbon or cellulose/conducting polymers aerogels can be facilely prepared by the solvent mixing method [25-27], and the doping content and $3 \mathrm{D}$ microporosity can be tunable during the gelification process $[28,29]$. For instance, a 3D CNFs/PANI aerogel electrode has been prepared by the supramolecular self-assembly method by mixing of CNFs and PANI nanocomposite suspension. Unfortunately, the maximum specific capacitance of CNF/PANI aerogel was only of $59.26 \mathrm{mF} / \mathrm{cm}^{2}$ at $10 \mathrm{mV} / \mathrm{s}$ [30]. CNFs/rGO/PPy aerogel electrodes were reported to have $1.77 \mathrm{mg} / \mathrm{cm}^{2}$ of the active materials and exhibited high areal capacitance of $400 \mathrm{mF} / \mathrm{cm}^{2}$ at $0.25 \mathrm{~mA} / \mathrm{cm}^{2}$, with the capacitor retention rate of only $75.6 \%$ [31]. Nanocellulose-supported hierarchical-structured polyaniline/nanocarbon nanocomposite aerogel electrodes have been prepared by via layer-by-layer assembly, which achieved high $1.59 \mathrm{~F} / \mathrm{cm}^{2}$ at a scan rate of $1 \mathrm{mV} / \mathrm{s}$ [32]. Even so, the specific capacitance, rate capability, and retention performance of these reported electrodes are still far from satisfactory for real applications in electronics. Further studies are still necessary to develop flexible cellulose-based electrodes with robust mechanical properties and superior electrochemical performance for flexible and wearable supercapacitors.

In this paper, natural and low-cost cotton linter pulp and commercial single-layer GO were used as raw materials. The regeneration of cellulose fibers and uniformly distribution of the GO nanosheets within the cellulose fibers were easily conducted in $\mathrm{LiBr}$ aqueous solution at $120^{\circ} \mathrm{C}$. Fortunately, $\mathrm{GO}$ was reduced during the solution processing. To make better use of the conductivity and flexibility of polyaniline, aniline was soaked and in-situ polymerized into this porous cellulose/GO hydrogel matrix to form binder-free composite electrodes. Such a green procedure provides a facile and scalable route for fabricating a robust and high porous 3D network of cellulose-based aerogel electrodes. The effects of different contents of GO and PANI on the electrical conductivity and electrochemical properties were investigated. Due to the three-dimensional porous structures, high conductivity, and remarkable wettability of cellulose/GO/PANI aerogel electrodes, the all-solid-state symmetric 
supercapacitor, assembled with $\mathrm{H}_{2} \mathrm{SO}_{4} /$ poly(vinyl alcohol) (PVA) gel as the electrolyte, can deliver an outstanding areal specific capacitance of $1858.7 \mathrm{mF} / \mathrm{cm}^{2}$ at $1.0 \mathrm{~mA} / \mathrm{cm}^{2}$ and high energy density up to $258.2 \mu \mathrm{Wh} / \mathrm{cm}^{2}$ at a power density of $1201.4 \mu \mathrm{W} / \mathrm{cm}^{2}$. Besides, the tandem devices can easily light up a red light-emitting diode for several minutes. These results indicate the cellulose/GO $\mathrm{G}_{3.5} / \mathrm{PANI}$ aerogel-based supercapacitors have excellent performance.

\section{Materials and Methods}

\subsection{Materials}

Cotton linter pulp $(\alpha$-cellulose $>95 \%$ and D.P. $=720$ ) was provided by Anhui Snow Dragon Fiber Tech. Co. Ltd. (Suzhou, China). Single-layer graphene oxide (GO) powder was obtained from Nanjing XFNANO Materials Tech Co. Ltd. (Nanjing, China) Lithium bromide (LiBr), aniline (ANI), and ammonia persulfate (APS) were purchased from Aladdin Chemical Co. (Shanghai, China). Other chemicals and reagents of analytical grade were purchased from Sinopharm Group Chemical Reagent Co. Ltd. (Shanghai, China) and used as received.

\subsection{Preparation of PANI/GO/Cellulose Composites}

Briefly, GO powder was added into a LiBr aqueous solution $(60 \mathrm{wt} . \%, 14 \mathrm{~mL})$ and ultrasonicated for half an hour to gain a uniform dispersion. Then, cotton linter pulp $(0.25 \mathrm{~g})$ was added and heated up to $120^{\circ} \mathrm{C}$ with vigorous stirring, until the cellulose was completely dissolved. After that, the mixture was allowed to gradually cool to become a homogeneous gelatinous form. The obtained cellulose/GO hydrogel blocks were immersed into the deionized water for about 2 days, and then cut into discs with $2 \mathrm{~mm}$ thickness and $17.15 \mathrm{~mm}$ diameter. Various amount of GO powder was used to keep GO content of 1.0, 2.0, 3.5, and $5 \mathrm{wt} . \%$ in the hydrogels, as denoted as cellulose/GO $\mathrm{G}_{1.0}$, cellulose/GO $\mathrm{GO}_{2.0}$, cellulose/ $\mathrm{GO}_{3.5}$, and cellulose/GO $\mathrm{GO}_{5.0}$, respectively. The pure cellulose hydrogel without $\mathrm{GO}$ was prepared for comparison.

To load the PANI conducting fillers, the hydrogel samples were soaked in an ANI/HCl solution (1 $\mathrm{M}$ ANI dissolved in $1 \mathrm{M} \mathrm{HCl}$ ) to ensure aniline molecules were fully dispersed in the pore of the hydrogel matrix. Subsequently, $10 \mathrm{~mL}$ of $\mathrm{APS} / \mathrm{HCl}$ acid solution $(1 \mathrm{M} / 1 \mathrm{M})$ was added and gently stirred continuously in an ice bath for $10 \mathrm{~h}$. Finally, the samples were taken out and rinsed with deionized water several times. Finally, the cellulose/PANI and cellulose/GO/PANI composites were obtained after freeze-drying.

\subsection{Fabrication of All-Solid-State Supercapacitors}

The PVA/ $\mathrm{H}_{2} \mathrm{SO}_{4}$ gel electrolyte was prepared according to our previous work [33]. Then, the PVA/ $\mathrm{H}_{2} \mathrm{SO}_{4}$ gel was pasted onto one side of aerogel electrodes; every two pieces were pressed together under $10 \mathrm{MPa}$ for $10 \mathrm{~min}$ to make sure the gel electrolyte was well combined. On the other side of the electrode, a silver paste was coated and the aluminum foil was connected. The working area was $2.31 \mathrm{~cm}^{2}$ and the thickness of the device was $0.1 \mathrm{~cm}$.

\subsection{Characterization of As-Prepared Materials}

Fourier Transform Infrared spectrum (FT-IR) was recorded on a Perkin-Elmer Spectrum One spectrometer (Perkin-Elmer, Shanghai, China) in a range of $4000-400 \mathrm{~cm}^{-1}$ using KBr pellets. The morphology observation of the samples was examined by a Hitachi SU-8010 field emission scanning electron microscope (Hitachi, Tokyo, Japan). Thermogravimetric analysis (TGA) was conducted on a NETZSCH STA 449 F3 instrument (NETZSCH, Shanghai, China), and the samples were heated up to $800{ }^{\circ} \mathrm{C}$ at a heating rate of $10^{\circ} \mathrm{C} / \mathrm{min}$ under nitrogen flow of $5 \mathrm{~mL} / \mathrm{min}$. X-ray photoelectron spectroscopy (XPS) analyses were carried out on an AXIS UltraKratos photoelectron spectrometer (SHIMADZU, Kyoto, Japan), utilizing a monochromatic $150 \mathrm{~W}$ Al X-ray source. Nitrogen adsorption isotherms were collected at $77 \mathrm{~K}$ using an autosorb iQ instrument (Quantachrome, Boynton Beach, FL, 
USA) volumetric gas adsorption analyzer. The specific surface area and the pore size distribution of the samples were calculated according to the Brunauer-Emmett-Teller (BET) and Barrett-Joyner-Halenda (BJH) methods, respectively. The electrical conductivity of aerogel samples was measured using the previously reported method [34,35]. Typically, the as-prepared samples were cut into $1 \mathrm{~cm} \times 1 \mathrm{~cm}$, and pressed at $10 \mathrm{MPa}$ for $10 \mathrm{~s}$. The thickness of the samples was estimated by using a micrometer. Bulk resistance $(R)$ of the samples was measured at room temperature using a digital multimeter. The conductivity, $\sigma$ was obtained from the equation: $\sigma=L /(R \times W \times d)$, where $L, W$, and $d$ refers to the length, width, and thickness in $\mathrm{cm}$, respectively.

The electrochemical characterizations were carried out on a CHI760E electrochemical workstation (CHI instrument, Shanghai, China). In a 3-electrode configuration, samples with $1 \times 1 \times 0.1 \mathrm{~cm}^{3}$ dimension, saturated calomel electrode and platinum plate are working, reference, and counter electrodes, respectively; $1 \mathrm{M} \mathrm{H}_{2} \mathrm{SO}_{4}$ aqueous solution was used as the electrolyte. Specifically, electrochemical impedance spectroscopy (EIS) spectra were conducted over a frequency range of $10 \mathrm{MHz}$ to $100 \mathrm{kHz}$ by with an AC sinusoid signal of $5 \mathrm{mV}$ amplitude. To calculate the areal specific capacitance $\left(C_{\mathrm{s}}\right.$ in $\left.\mathrm{mF} \mathrm{cm}^{-2}\right)$ and Coulombic efficiency $(\eta)$, the following equations were used [36,37]:

$$
\begin{gathered}
C_{\mathrm{s}}=\frac{I \times t}{\mathrm{~S} \times \Delta V} \\
\eta=\frac{t_{\mathrm{D}}}{t_{\mathrm{C}}} \times 100 \%
\end{gathered}
$$

where $I$ is the charge-discharge current $(\mathrm{mA}), t$ represents the discharge time $(\mathrm{s}), \mathrm{S}$ is the area of the electrode $\left(\mathrm{cm}^{2}\right)$, and $\Delta V$ is the potential window of the discharge curve excluding initial drop $(\mathrm{V})$. For the symmetric supercapacitor device, the areal specific capacitance $\left(C_{\mathrm{a}} \mathrm{in} \mathrm{mF} \mathrm{cm}{ }^{-2}\right)$, the energy

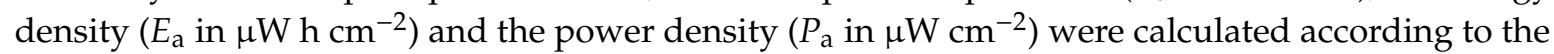
following equations [36-39]:

$$
\begin{gathered}
C_{\mathrm{a}}=\frac{2 I \times t}{\mathrm{~S} \times \Delta V} \\
E_{\mathrm{a}}=\frac{0.5 C_{\mathrm{a}} \Delta V^{2}}{3.6} \\
P_{\mathrm{a}}=\frac{3600 E_{\mathrm{a}}}{t}
\end{gathered}
$$

\section{Results and Discussion}

\subsection{Preparation, Morphology, and Structure of the Ternary Cellulose/GO/PANI Composite}

As illustrated in Figure 1, the cellulose/GO/PANI composite was prepared in three steps, including dissolving cotton linter pulp and dispersing GO simultaneously into the aqueous solution of $\mathrm{LiBr}$, adsorption of aniline monomer onto the network, and in-situ polymerization of the PANI component. The regeneration of the cellulose/GO hydrogel was a black block, and then it was cut into thin sheets with a thickness of roughly $2.0 \mathrm{~mm}$. The black sheets turned dark green after the growth of PANI in the 3D networks. Due to the coating of hydrophobic PANI on the surface of the sheets, wettability was evaluated by distilled water contact angles method. As shown in the bottom of Figure 1, a water droplet penetrates into the cellulose/GO $\mathrm{GO}_{3.5} / \mathrm{PANI}$ sample instantly. This phenomenon could be due to the sufficient porosity on the smooth surface of the sheet. Although the contact angle was undetectable, the super wettability of this cellulose-based surface will promote the electrolyte receptivity that is favorable for the electrochemical performance. 


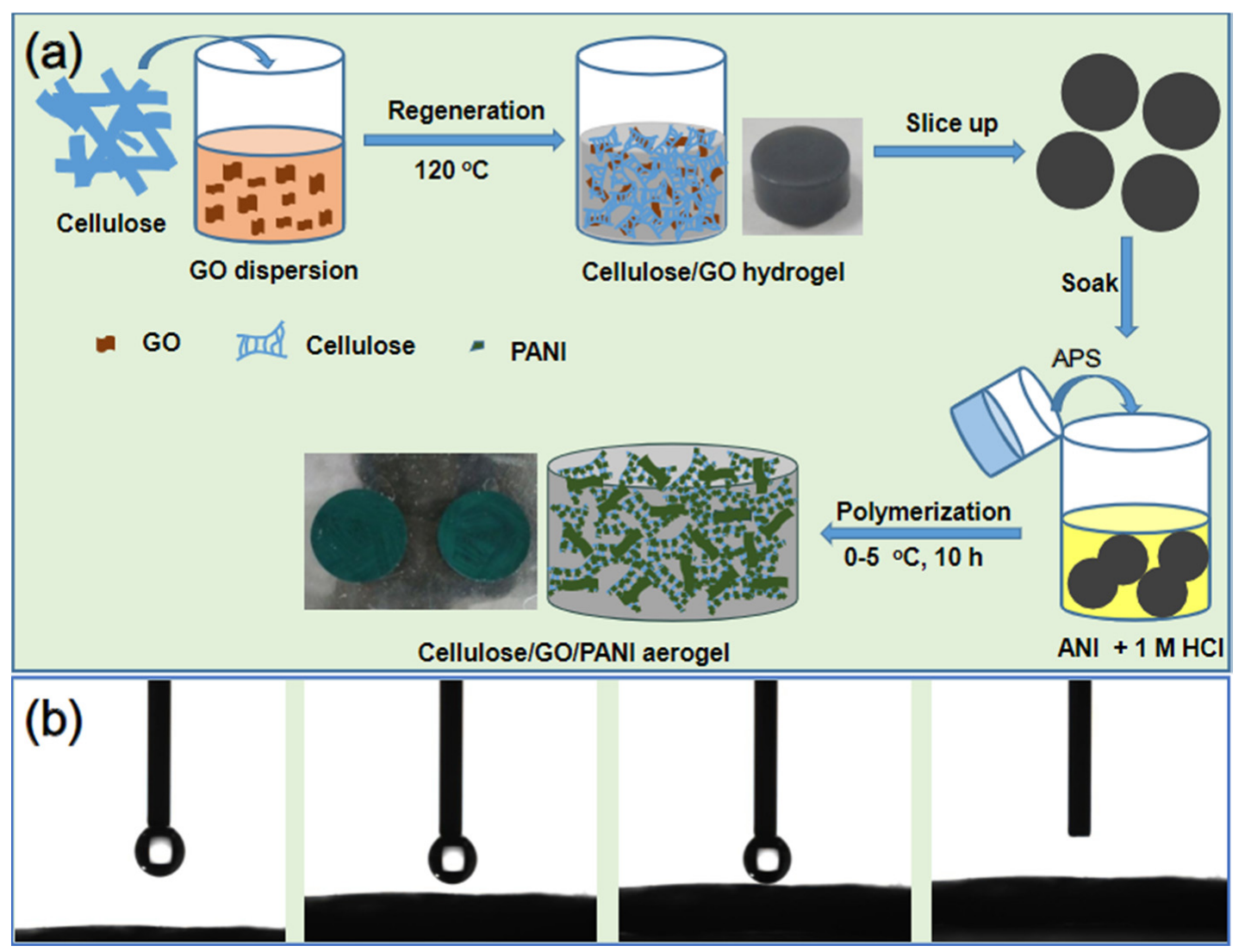

Figure 1. (a) Synthetic pathway of the cellulose/ graphene oxide (GO)/ Polyaniline (PANI) composites. (b) The water droplet contact process on the surface of the cellulose/ $\mathrm{GO}_{3.5} / \mathrm{PANI}$ composite.

The chemical composition of the obtained samples was characterized by FT-IR spectroscopy. As presented in Figure 2a, the regenerated cellulose and GO samples exhibit several absorption peaks in good agreement with those reported elsewhere $[33,40]$. When doped with a small amount of GO with cellulose, the cellulose/GO composite exhibits all the characteristic peaks corresponding to cellulose and GO, except that the characteristic peak of carbonyls $(\mathrm{C}=\mathrm{O})$ at $1730 \mathrm{~cm}^{-1}$ decreased dramatically, indicating the reduction of the oxygen functional groups [41].The neat PANI showed the absorption peaks at 1575, 1490, and $1132 \mathrm{~cm}^{-1}$, assignable to the characteristic vibrations of the benzene ring, the peak at 1297 and $799 \mathrm{~cm}^{-1}$ corresponding to the $\mathrm{C}-\mathrm{N}$ stretching and $\mathrm{C}-\mathrm{H}$ out-of-plane bending vibrations, respectively. However, the peaks located at 1575, 1297, and $1132 \mathrm{~cm}^{-1}$ of PANI show an obvious blue shift to 1588,1312 , and $1153 \mathrm{~cm}^{-1}$ in the spectrum of the cellulose/GO $\mathrm{GO}_{3.5} / \mathrm{PANI}$ sample, suggesting the $\pi-\pi$ interaction exists between the GO and conjugated structure of the PANI, which would strengthen the electrical conductivity of the materials [42,43]. Additionally, the absorption peak at $3430 \mathrm{~cm}^{-1}$ due to the stretching vibration of $\mathrm{OH}$ groups in cellulose $/ \mathrm{GO}_{3.5}$ sample is down-shifted to $3375 \mathrm{~cm}^{-1}$ in cellulose $/ \mathrm{GO}_{3.5} / \mathrm{PANI}$ sample, which indicates the existence of strong hydrogen bonding interaction among the three components [44]. 

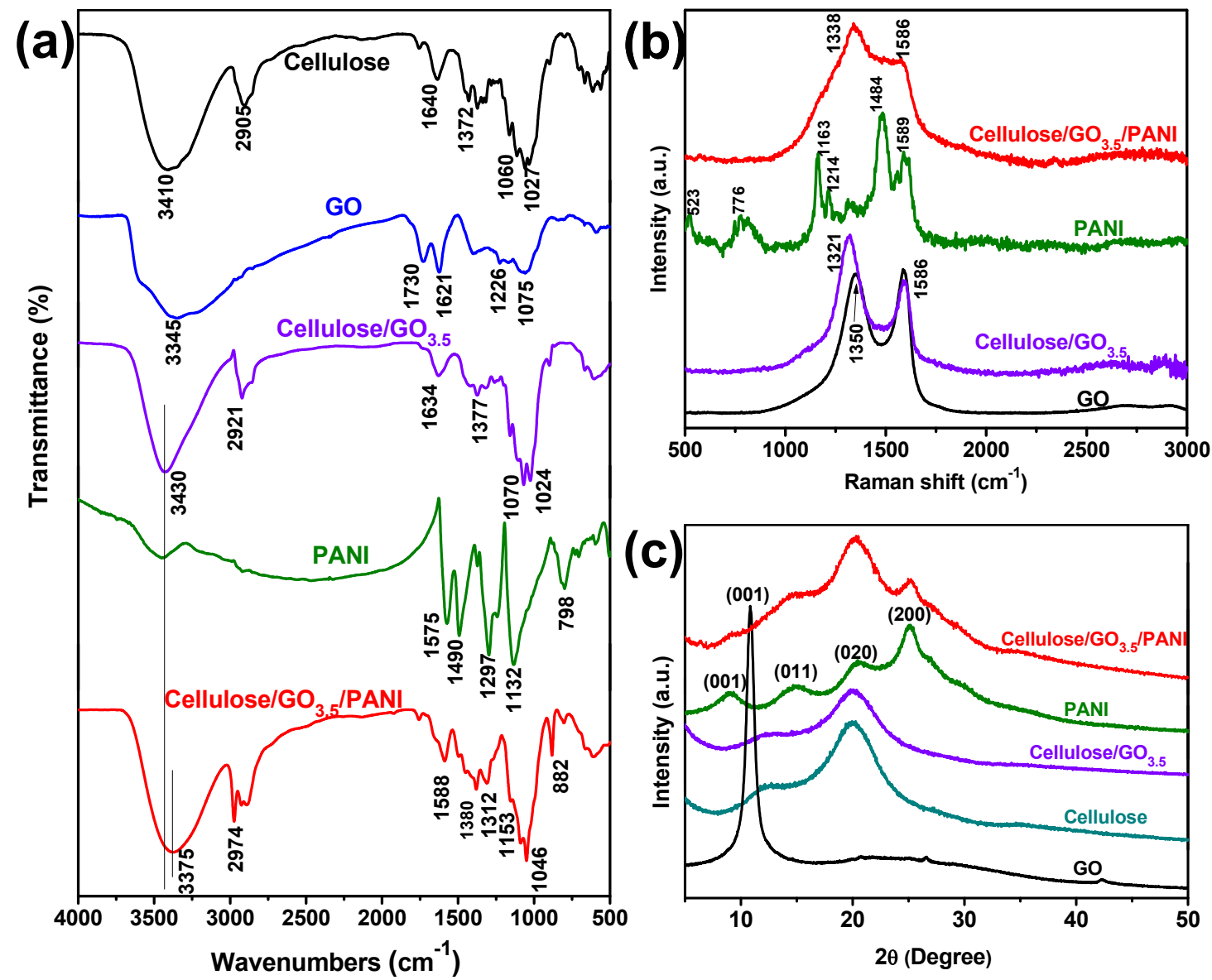

Figure 2. (a) Fourier Transform Infrared spectrum (FT-IR), (b) Raman, and (c) X-ray diffraction (XRD) spectra of neat cellulose, GO, PANI, cellulose/ $\mathrm{GO}_{3.5}$ and cellulose/GO $\mathrm{GO}_{3.5} / \mathrm{PANI}$ composites.

Raman spectroscopy was used to reflect the structural details of the ternary composite. Raman spectra of GO, PANI, cellulose/ $\mathrm{GO}_{3.5}$, and cellulose/GO $\mathrm{GO}_{3.5} / \mathrm{PANI}$ composites are demonstrated in Figure $2 \mathrm{~b}$. Typically, GO exhibited the characteristic D band at $1350 \mathrm{~cm}^{-1}$ and $\mathrm{G}$ band at $1586 \mathrm{~cm}^{-1}$. Nevertheless, with the thermal blending process in the $\mathrm{LiBr}$ solution, the $\mathrm{D}$ band of the cellulose/GO $\mathrm{GO}_{3.5}$ showed a noticeable downshift to $1321 \mathrm{~cm}^{-1}$, along with an obvious increase in $\mathrm{I}_{\mathrm{D}} / \mathrm{I}_{\mathrm{G}}$ of 1.47 from original 0.973 . These observations suggested the thermal reduction of GO and the existence of highly disordered structures in the as-prepared cellulose/ $\mathrm{GO}_{3.5}$ sample [45]. Further, after cooperation with PANI, the cellulose $/ \mathrm{GO}_{3.5} / \mathrm{PANI}$ composite showed mainly typical bands around 1338 and $1586 \mathrm{~cm}^{-1}$, which is attributable to the $\mathrm{C}-\mathrm{N} / \mathrm{C}=\mathrm{N}$ and $\mathrm{C}-\mathrm{C}$ bonds, respectively. These broad bands should have overlaid characteristic peaks of GO and PANI, indicating the complete wrapping of GO nanosheets and cellulose nanofibers by PANI [19].

X-ray diffraction of neat cellulose, $\mathrm{GO}, \mathrm{PANI}$, cellulose/ $\mathrm{GO}_{3.5}$, and cellulose/GO $\mathrm{G}_{3.5} / \mathrm{PANI}$ composites are shown in Figure 2c. GO mainly displayed an intense characteristic peak at $11^{\circ}$ corresponding to the (001) reflection peak. The cellulose/GO 3.5 sample exhibited similar X-ray diffraction (XRD) spectrum to that of the pure cellulose, in which diffraction peaks appeared at $2 \theta=16.5^{\circ}, 22.9^{\circ}$, and $34.8^{\circ}$ [46], indicating the crystalline type of cellulose is not altered after being doped with GO and the following regeneration. The absence of the characteristic peak at $11^{\circ}$ is due to the low content and the thermal reduction as mentioned in Raman analysis. The pure PANI exhibited four distinct peaks centered around $8.9^{\circ}, 15.2^{\circ}, 20^{\circ}$, and $25.3^{\circ}$, which is assignable to (001), (011), (020), and (200) crystal planes of PANI in its emeraldine salt form [47]. In the XRD pattern for cellulose/ $\mathrm{GO}_{3.5} / \mathrm{PANI}$ composite, not only was the characteristic diffraction peak of cellulose observed at $22.9^{\circ}$, but also low-intensity diffraction peaks of PANI at $15.2^{\circ}$ and $25.3^{\circ}$, which indicates the presence of PANI in the ternary composites. 
However, the intensity of the diffraction peaks of the cellulose/GO $\mathrm{GO}_{3.5} / \mathrm{PANI}$ composite is apparently decreased. It turns out again that the strong interactions among these components have limited the re-crystallization of the composite aerogel [48].

The chemical bonding in the cellulose/GO $\mathrm{GO}_{3.5} / \mathrm{PANI}$ composite was further analyzed by XPS measurements. The XPS survey spectrum of GO, PANI, and the cellulose/GO $\mathrm{GO}_{3.5} / \mathrm{PANI}$ composite are presented in Figure 3a. Typically, except for $\mathrm{C}$ and $\mathrm{O}$ elements, extra elements of nitrogen, chloride, and sulfur are noted in the cellulose/GO $\mathrm{G}_{3.5} / \mathrm{PANI}$ composite. It is noteworthy that the peak related to the element sulfur is due to the residue from a trace of APS. The deconvolution of $C$ 1s spectra of PANI and the cellulose/ $\mathrm{GO}_{3.5} / \mathrm{PANI}$ composite are presented in Figure $3 \mathrm{~b}$. The major peak line of PANI can be decomposed into four peak lines: $284.6 \mathrm{eV}(\mathrm{C}-\mathrm{C} / \mathrm{C}=\mathrm{C}, 33.72 \%), 285.6 \mathrm{eV}(\mathrm{C}-\mathrm{N}, 38.44 \%), 286.6 \mathrm{eV}$ $\left(\mathrm{C}=\mathrm{N} / \mathrm{C}=\mathrm{N}^{+}, 22.31 \%\right)$, and $288.1 \mathrm{eV}(\mathrm{C}=\mathrm{O}, 5.53 \%)$ [49]. The $\mathrm{C}=\mathrm{O}$ functional groups present in PANI might be assigned to the formation of benzoquinone and hydroquinone [50] as products of the partial surface oxidation during handling. While the $\mathrm{C} 1 \mathrm{~s}$ core-level spectrum of the cellulose/GO $\mathrm{G}_{3.5} / \mathrm{PANI}$ sample can be curve-fitted into five subpeaks (Figure 3c): $284.8 \mathrm{eV}(\mathrm{C}-\mathrm{C} / \mathrm{C}=\mathrm{C}, 21.63 \%), 285.8 \mathrm{eV}$ $(\mathrm{C}-\mathrm{N}, 24.99 \%), 286.6\left(\mathrm{C}=\mathrm{N} / \mathrm{C}=\mathrm{N}^{+}, 10.70 \%\right), 287.2(\mathrm{C}-\mathrm{O}, 22.27 \%)$, and $288.1(\mathrm{C}=\mathrm{O}, 20.42 \%)$ (Figure 3b). The relatively higher ratio of $\mathrm{C}=\mathrm{N} / \mathrm{C}=\mathrm{N}^{+}$to $\mathrm{C}-\mathrm{N}$ bonds in the ternary composite $(43 \%)$ is found much lower than that for pure PANI (58\%), which could be related to the interactions of the amine groups of the PANI with oxygen functional groups of GO [49]. This observation further supports the presence of strong interactions in line with the FT-IR and XRD characterizations. In addition, the N 1s XPS spectrum of the pure PANI sample is deconvoluted into four peaks at $398.3 \mathrm{eV}(=\mathrm{N}-, 2.21 \%), 399.8 \mathrm{eV}$ $(-\mathrm{NH}-, 75.69 \%), 401.4 \mathrm{eV}\left(\mathrm{N}^{+}, 16.10 \%\right)$, and $403.0 \mathrm{eV}\left(-\mathrm{NH}^{+}, 6.00 \%\right)$. All four types of amine structure can be found in the $\mathrm{N}$ 1s spectrum of the cellulose/GO/PANI composite with different contents of $2.12 \%, 68.18 \%, 20.64 \%$, and $9.10 \%$, respectively. Specifically, the sum of positively charged nitrogen in the composite is higher than that in pure PANI, indicating a relatively higher doping level of PANI in the composite. The increased proportion of positively charged nitrogen could be ascribed to the interactions between PANI and GO that leads to the restructuring of the benzenoid amine structure of PANI [51], which is also in accordance with the result of the C 1s spectra analysis. Additionally, the high doping level of PANI in this composite is expected to enhance its pseudocapacitive performance as electrode materials [52].

The thermal properties and the content of the PANI (in weight ratio) in the cellulose/GO $\mathrm{G}_{3.5} / \mathrm{PANI}$ sample were determined by thermogravimetrical analysis, with the regenerated cellulose, GO, PANI, as well as the cellulose $/ \mathrm{GO}_{3.5}$ composite used as references. As presented in Figure $3 \mathrm{~d}$, a weight loss of $\sim 5 \mathrm{wt} . \%$ for all samples up to a temperature of $100{ }^{\circ} \mathrm{C}$ is due to the evaporation of physisorbed water. The cellulose aerogel was thermally stable up to $210^{\circ} \mathrm{C}$; a major weight loss commenced from 210 to $450{ }^{\circ} \mathrm{C}$ could be attributed to the pyrolysis of the molecular fragment, such as $-\mathrm{OH}$ and $-\mathrm{CH}_{2}-\mathrm{OH}$, and finally decomposed of the main chains. As incorporated with a small amount of GO, the cellulose/ $\mathrm{GO}_{3.5}$ composite exhibits a slightly higher mass loss than that of neat cellulose, which is associated with the removal of labile oxygen functional groups of GO [53]. Pure PANI is known to degrade in a three-stage weight loss profile, where the weight loss step at $100-300{ }^{\circ} \mathrm{C}$ is attributed to the loss of the dopant ions (weight loss of $6 \%$ ), and the final step $\left(>400^{\circ} \mathrm{C}\right)$ with the weight loss of $36 \%$ corresponds to the degradation of backbone chains of the polymer. Interestingly, the TGA profiles of the ternary composite exhibit similar curve features of PANI. With the combination of PANI, the ternary composite is relatively more thermal stable; the degradation rate is much slower than that of cellulose/ $\mathrm{GO}_{3.5}$ aerogel. The gradual loss in the region at $400-650{ }^{\circ} \mathrm{C}$ is estimated to be ca. $15 \mathrm{wt} . \%$, which is easily attributable to the weight fraction of PANI in the ternary composite of cellulose/ $\mathrm{GO}_{3.5} / \mathrm{PANI}$. Additionally, as can be seen in DTG curves, $T_{\max }$ of PANI was found at $512{ }^{\circ} \mathrm{C}$; however, the corresponding peak in the cellulose/ $\mathrm{GO}_{3.5} / \mathrm{PANI}$ composite was up-shifted to $530^{\circ} \mathrm{C}$. The phenomenon could be related to the establishment of hydrogen bonds of PANI with the cellulose and strong $\pi-\pi$ interaction with GO components, resulting in the formation of mechanical stable nanocomposites. 

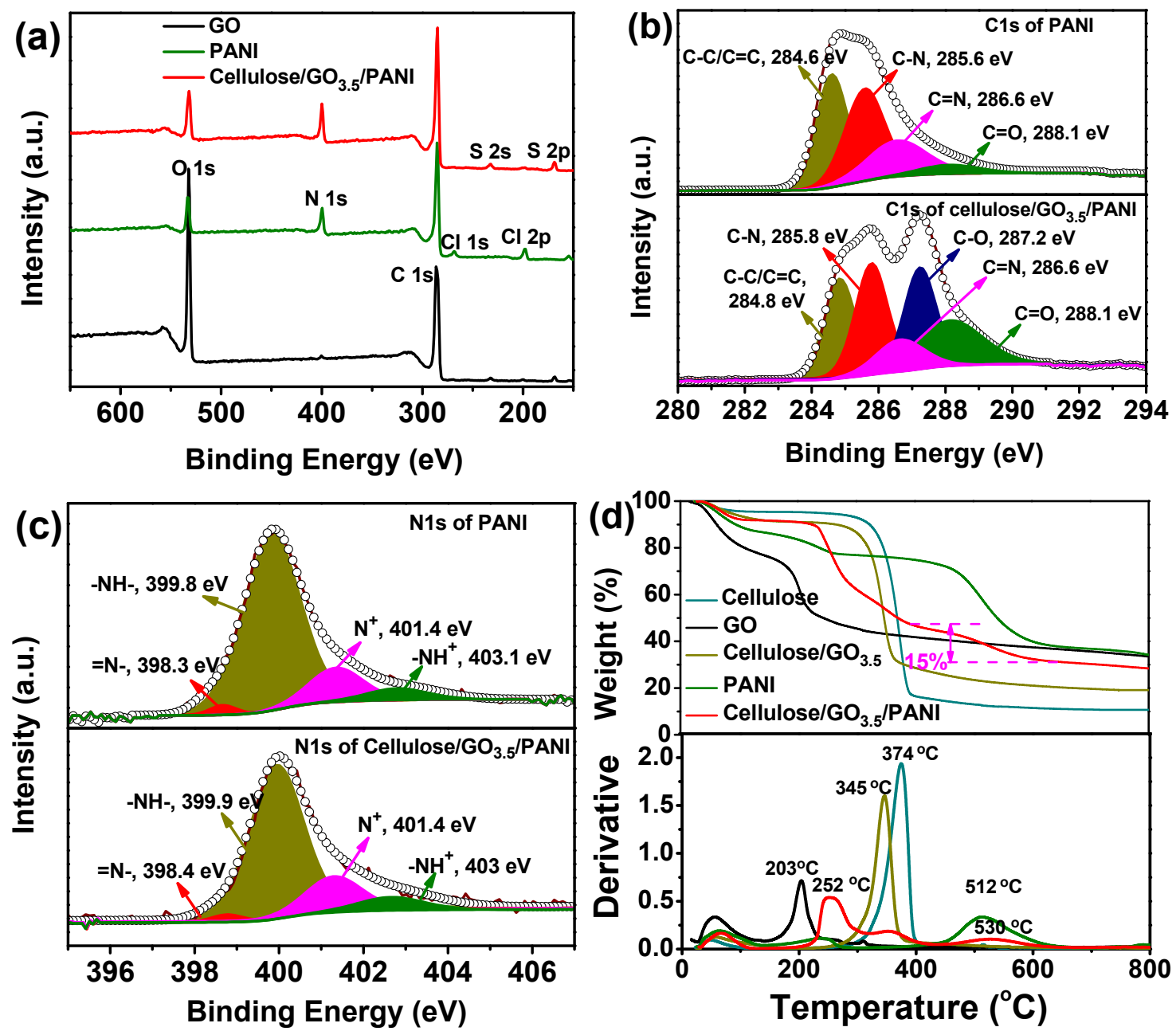

Figure 3. (a) X-ray photoelectron spectroscopy (XPS) survey spectra of the pristine GO, neat PANI, and the cellulose/GO $\mathrm{GO}_{3.5} / \mathrm{PANI}$ composite. (b) Comparison of $\mathrm{C} 1 \mathrm{~s}$ spectra of PANI and the cellulose/GO $\mathrm{GO}_{3.5} / \mathrm{PANI}$ composite. (c) $\mathrm{N} 1 \mathrm{~s}$ spectra of the cellulose/ $\mathrm{GO}_{3.5} / \mathrm{PANI}$ composite and pure PANI. (d) Thermogravimetric analysis (TGA) pattern of pure cellulose, GO, PANI, cellulose/GO $\mathrm{GO}_{3.5}$, and cellulose/GO $3.5 / \mathrm{PANI}$ samples.

The digital image in Figure 4a shows free-standing films of the prepared cellulose, cellulose/GO $\mathrm{G}_{3.5}$, and cellulose/ $\mathrm{GO}_{3.5} / \mathrm{PANI}$ samples. PANI could be seen throughout the cellulose $/ \mathrm{GO}_{3.5} / \mathrm{PANI}$ sample with relatively low reflectivity, suggesting uniformity in monomer infiltration and growth. The ternary cellulose/GO $\mathrm{GO}_{3.5} / \mathrm{PANI}$ sample has very good flexibility, showing to be bendable in Figure $4 \mathrm{~b}$. The inner morphological details of the pure cellulose, cellulose $/ \mathrm{GO}_{3.5}$, and the cellulose/GO $\mathrm{G}_{3.5} / \mathrm{PANI}$ composite were characterized by field emission scanning electron microscopes (FE-SEM). The cross-section view of the regenerated cellulose sample shows a network-like and 3D porous structure (Figure 4c-e), and the surface of cellulose nanowhiskers is relatively neat at high magnification. Apparent changes were noticed in the morphology of the cellulose/GO $\mathrm{GO}_{3.5}$ aerogel (Figure $4 \mathrm{f}-\mathrm{h}$ ), in which GO sheets partly fill the micropores to form a smooth wall for macropores. In detail, some smaller GO sheets also attach to the cellulose fiber-like nodes. After the in-situ polymerization of ANI with $\mathrm{HCl}$ as dopant, the porous and spongy structure has persevered. PANI, in the form of nanoclusters, grew on the network of cellulose $/ \mathrm{GO}_{3.5}$, forming loose beaded chains with many interspaces remaining. It is believed that this composite should have a higher specific surface area than bulk materials to facilitate the effective access of the electrolyte ions [54]. Given the above chemical structure and morphology analysis, despite the hydrophobic character of PANI and the hydrophilic character of cellulose, the ternary composites have shown good miscibility and numerous electro-active clusters have been uniformly loaded in the 3D structure. 

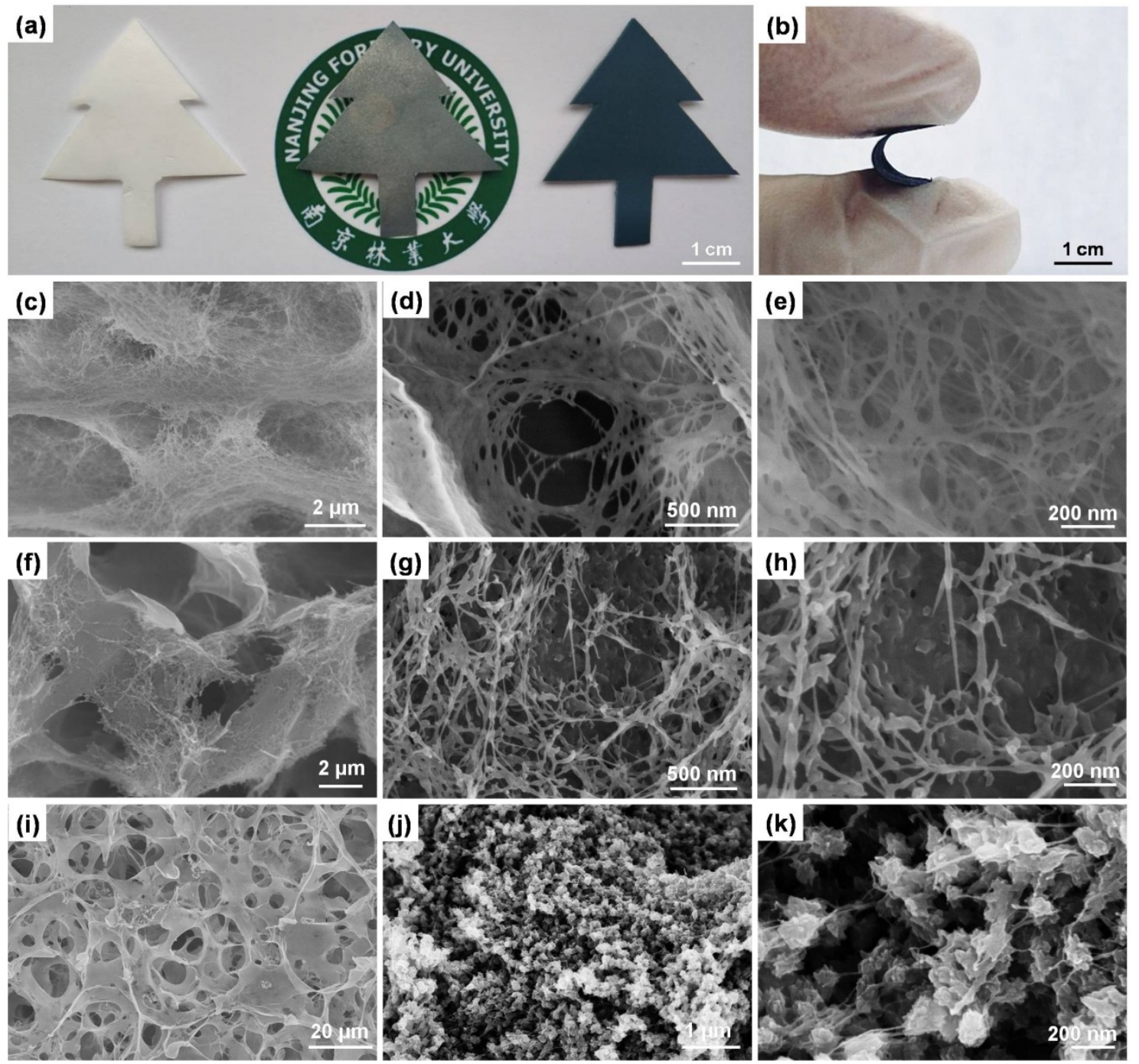

Figure 4. (a) Digital image of the pure cellulose (left), cellulose/GO $\mathrm{GO}_{3.5}$ (middle), and cellulose/ $\mathrm{GO}_{3.5} / \mathrm{PANI}$ (right) cut in a tree shape. (b) Digital photograph of the cellulose/ $\mathrm{GO}_{3.5} / \mathrm{PANI}$ under bending. Field emission scanning electron microscopes (FE-SEM); images of pristine cellulose sample (c-e), cellulose/GO $\mathrm{G}_{3.5}$ sample (f-h), and cellulose/ $\mathrm{GO}_{3.5} / \mathrm{PANI}$ sample (i-k) at different magnifications.

The gas adsorption-desorption isotherms for the as-prepared cellulose, cellulose/ $\mathrm{GO}_{3.5}$, cellulose/ PANI, and cellulose/ $\mathrm{GO}_{3.5} / \mathrm{PANI}$ aerogel samples were carried out by the Brunauer-Emmett-Teller (BET) technique (Figure 5). All samples show type II adsorption isotherms, indicating the presence of many macropores and mesopores. BET and BJH analyses (Table 1) revealed that the regenerated cellulose sample had a well-defined mesopore of $10.9 \mathrm{~nm}$, and high-specific surface area of $137.6 \mathrm{~m}^{2} / \mathrm{g}$ and a total pore volume of $0.38 \mathrm{~cm}^{3} / \mathrm{g}$. While doped with GO, the surface area and pore feature showed a slight increase, which is resulted from the fact that the presence of graphene sheets can reinforce cellulose nanofibers to reduce shrinkage of aerogel during freeze-drying. Due to the deposition of PANI on cellulose nanofibers, the measured surface area for the cellulose/PANI is much lower than that of the regenerated cellulose, indicating the mesoporous channels could have been partially blocked. Likewise, the cellulose $/ \mathrm{GO}_{3.5} / \mathrm{PANI}$ composite shows a surface area of $66.7 \mathrm{~m}^{2} / \mathrm{g}$, which is $55 \%$ lower than that of the cellulose $/ \mathrm{GO}_{3.5}$ sample. The pore size distribution of the cellulose/ $\mathrm{GO}_{3.5} / \mathrm{PANI}$ sample presented a wide distribution of pores from micro to meso ranges, with the average pore size of $22.5 \mathrm{~nm}$, which is the highest one among the tested samples. It is believed that the adequate pore size and large total pore volume of cellulose/ $\mathrm{GO}_{3.5} / \mathrm{PANI}$ composites would be beneficial to electrochemical performances, 
because they provide fast ion transportation pathways through the nanopores of electrode materials during the electrochemical tests [55].
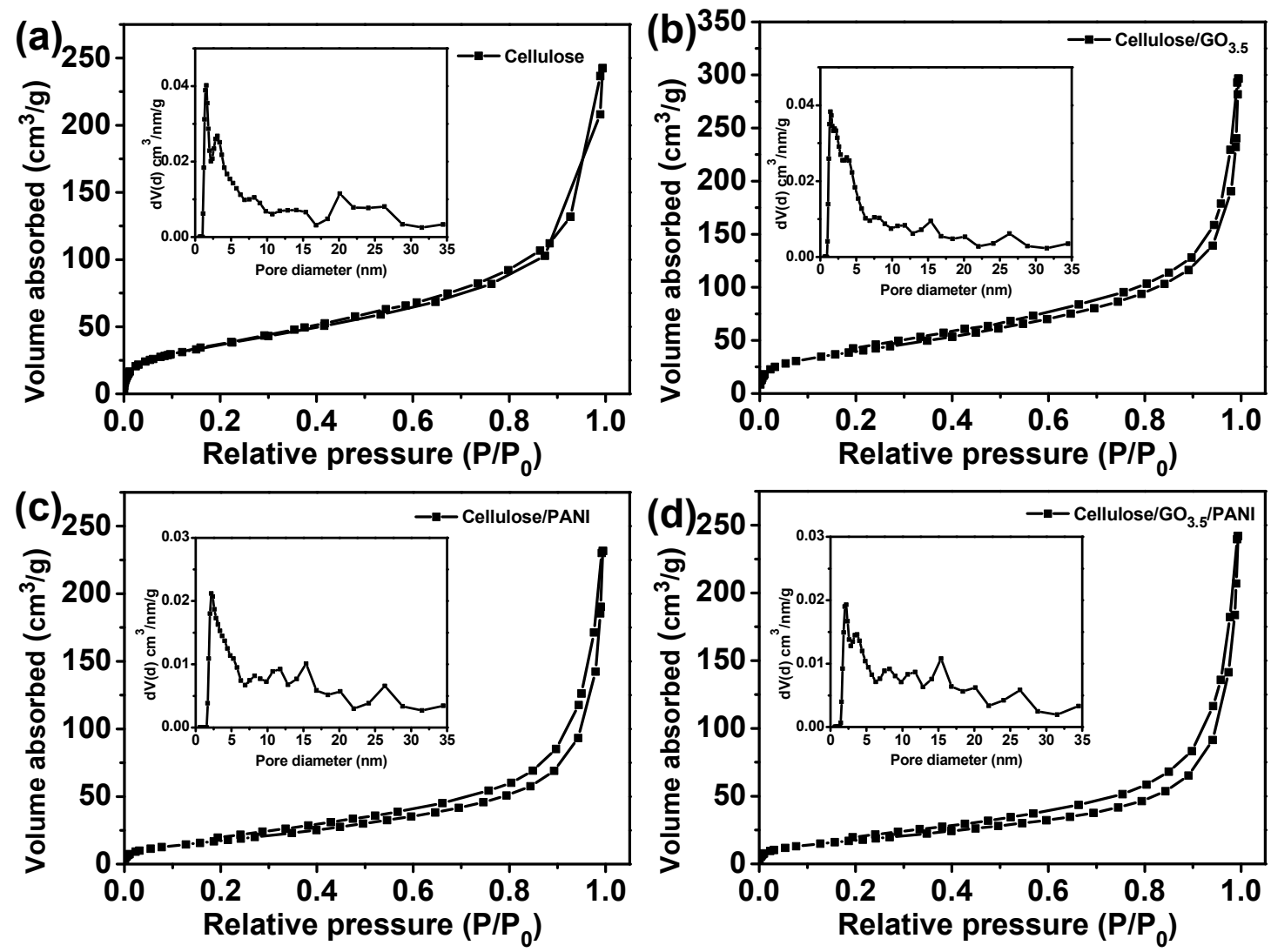

Figure 5. $\mathrm{N}_{2}$ sorption isotherms of the regenerated cellulose (a), cellulose/GO $\mathrm{GO}_{3.5}$ (b), cellulose/PANI (c), and cellulose/ $\mathrm{GO}_{3.5} / \mathrm{PANI}$ (d) samples. Inset is the corresponding pore size distribution.

Table 1. Brunauer-Emmett-Teller (BET) analysis of the regenerated cellulose, cellulose/ $\mathrm{GO}_{3.5}$, cellulose/ PANI and cellulose/ $\mathrm{GO}_{3.5} / \mathrm{PANI}$.

\begin{tabular}{|c|c|c|c|}
\hline Sample & $\mathrm{S}_{\mathrm{BET}}$ & Pore Volume $\left(\mathrm{cm}^{3} / \mathrm{g}\right)$ & Pore Size (nm) \\
\hline cellulose & 137.6 & 0.38 & 10.9 \\
\hline cellulose/ $\mathrm{GO}_{3.5}$ & 147.0 & 0.46 & 12.5 \\
\hline cellulose/PANI & 68.7 & 0.36 & 20.8 \\
\hline cellulose/ $\mathrm{GO}_{3.5} / \mathrm{PANI}$ & 66.7 & 0.37 & 22.5 \\
\hline
\end{tabular}

\subsection{Conductivity and Electrochemical Properties of Cellulose/GO/PANI Composite Electrodes}

Conductivity measurements on the various cellulose/GO $\mathrm{GO}_{1.0} / \mathrm{PANI}$, cellulose/GO $\mathrm{GO}_{2.0} / \mathrm{PANI}$, cellulose/ $\mathrm{GO}_{3.5} / \mathrm{PANI}$, and cellulose/GO $\mathrm{G}_{5.0} / \mathrm{PANI}$ samples indicated an average electrical conductivity of $0.50,0.82$, 1.15 , and $0.35 \mathrm{~S} / \mathrm{cm}$, respectively. The obtained high overall conductivity of the cellulose/GO $\mathrm{G}_{3.5} / \mathrm{PANI}$ sample ensures the use as a wire to light up a LED lamp (Figure S1), even at bending and foldable deformations. Further, the cyclic voltammogram (CV) tests for these samples were run to explore the effect of the GO content on the electrochemical performance of the ternary composite electrodes, as shown in Figure S2a. As the GO content increased, the area surrounded by the CV curves was not enlarged tremendously. Based on the conductivity and CV performance, the ternary sample with GO content of $3.5 \mathrm{wt} . \%$ has shown promising electrical properties among the ternary composites. As anticipated, the cellulose/ $\mathrm{GO}_{3.5} / \mathrm{PANI}$ electrode exhibits an enhanced remarkable electrical response when compared with cellulose/GO $\mathrm{GO}_{3.5}$ and cellulose/PANI electrodes (Figure 6a), which can be attributed to the synergistic effect of graphene and PANI as conducting fillers [6]. Meanwhile, the redox current 
density of this sample becomes larger and larger as the scan rate increased, indicating a good rate capability of the electrode. Two pairs of redox peaks of PANI can be observed at a low rate; however, they vanished at high scan rates, which are attributed to the existence of internal active sites that may not completely carry out redox transition, resulting in the variation of volt-ampere current at high scanning rate.
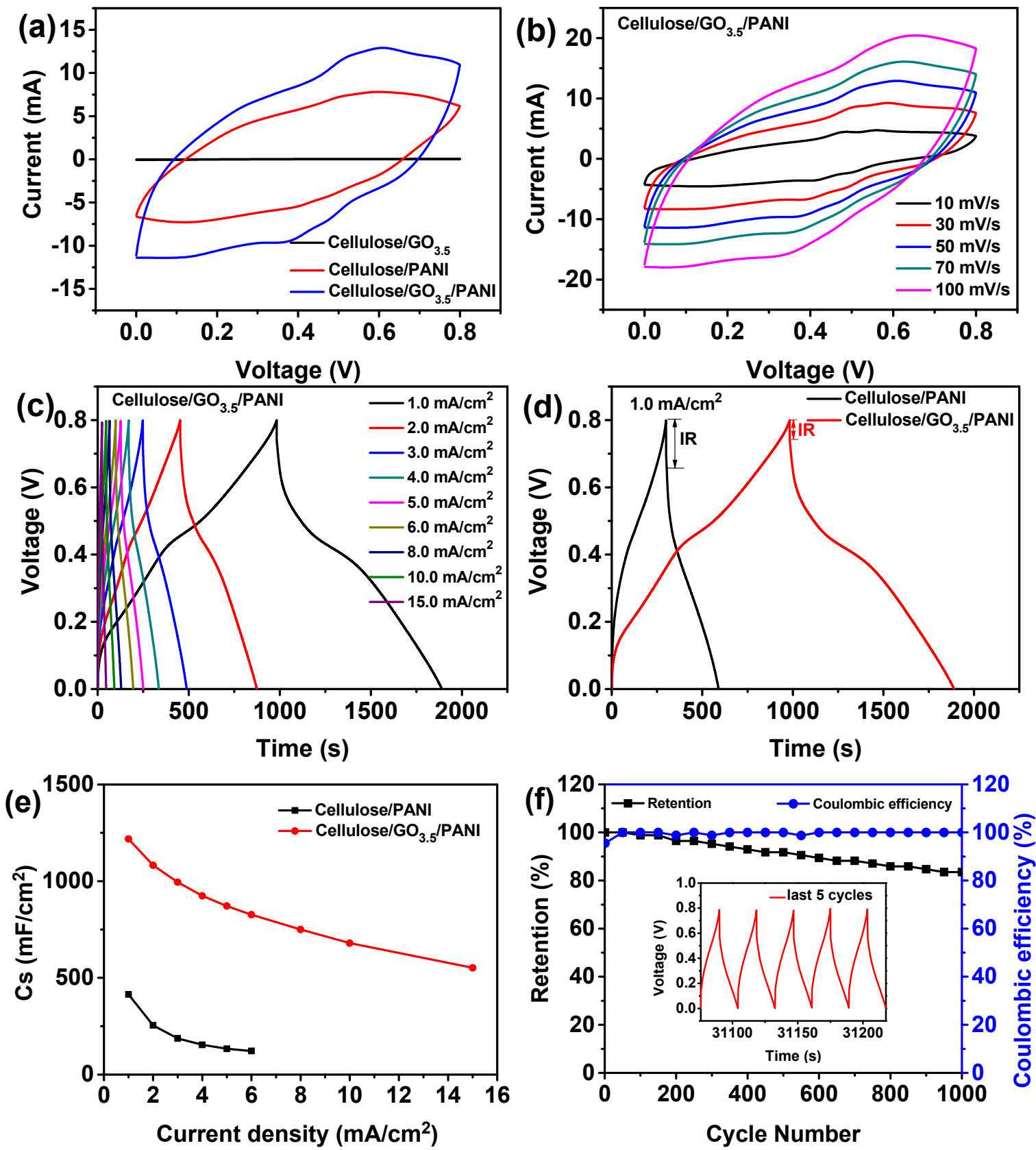

Figure 6. (a) Typical cyclic voltammogram (CV) curves of the cellulose/GO $\mathrm{GO}_{3.5}$, cellulose/PANI, and cellulose $/ \mathrm{GO}_{3.5} / \mathrm{PANI}$ electrodes at $50 \mathrm{mV} / \mathrm{s}$. (b) $\mathrm{CV}$ profiles of the cellulose/ $\mathrm{GO}_{3.5} / \mathrm{PANI}$ electrode at various sweep rates. (c) Galvanostatic charge-discharge (GCD) curves of the cellulose/GO ${ }_{3.5} / \mathrm{PANI}$ electrode at different current densities. (d) Comparative GCD curves of cellulose/PANI and cellulose/ $\mathrm{GO}_{3.5} / \mathrm{PANI}$ at a current density of $1.0 \mathrm{~mA} / \mathrm{cm}^{2}$. (e) Plots of areal specific capacitance vs. current density. (f) Cyclic stability and Coulombic efficiency $(\eta)$ of the cellulose/ $/ \mathrm{GO}_{3.5} / \mathrm{PANI}$ electrode at a current density of $15 \mathrm{~mA} / \mathrm{cm}^{2}$. The inset demonstrates the GCD curve for the last five cycles. 
The charge storage properties were further investigated by the galvanostatic charge-discharge (GCD) measurements. The GCD profiles of the cellulose/GO $\mathrm{G}_{3.5} / \mathrm{PANI}$ electrode at various current densities show nonlinear shape with two voltage stages in the discharge process (Figure 6c). At relative lower current densities of $1.0 \mathrm{~mA} / \mathrm{cm}^{2}$, the former stage $(0.8-0.45 \mathrm{~V})$ with relatively short discharge time is ascribed to the electrochemical double layer capacitor (EDLC), while the later stage (0.45-0 V) with much longer discharge time is associated with a combination of EDLC and pseudocapacitive capacitance. A typical comparison of GCD curves of the cellulose/PANI and cellulose/GO $3.5 / \mathrm{PANI}$ composite electrode is presented in Figure 6d. Benefiting from the presence of GO, the potential drop at the beginning of the discharge curve (called "IR drop") of the cellulose/GO $\mathrm{GO}_{3.5} / \mathrm{PANI}$ composite is much lower than that of the cellulose/PANI electrode, revealing lower internal resistance of cellulose/GO $\mathrm{GO}_{3.5} / \mathrm{PANI}$ composite than cellulose/PANI composite. According to Equation (1), the areal specific capacitance of cellulose $/ \mathrm{GO}_{3.5} / \mathrm{PANI}$ composite is found to be $1218 \mathrm{mF} / \mathrm{cm}^{2}$ at the current density of $1.0 \mathrm{~mA} / \mathrm{cm}^{2}$. Similar calculations were done for the cellulose/PANI electrode; however, much lower areal specific capacitance was found (Figure 6e), thus confirming the high loading capacity of the cellulose $/ \mathrm{GO}_{3.5} / \mathrm{PANI}$ composite. Actually, to evaluate the contribution of PANI to energy storage, a series of ternary cellulose/GO/PANI samples (GO of $3.5 \mathrm{wt} . \%$ ) were prepared from different aniline concentrations of $0.5,0.75,1.0$, and $1.25 \mathrm{M}$. Their electrochemical performances along with comparison with those of the cellulose/ $\mathrm{GO}_{3.5} / \mathrm{PANI}$ electrode are presented in Figure S3. The largest enclosed area and the longest charging/discharging time of the cellulose/GO $\mathrm{GO}_{3.5} / \mathrm{PANI}$ electrode indicates the best capacitive performance among the four samples. Ideal performance on the cellulose/GO $\mathrm{G}_{3.5} / \mathrm{PANI}$ electrode may be due to its unique pore structure and the appropriate size of PANI nanoclusters. When the aniline concentration increased to $1.25 \mathrm{M}$, the thicker coating layer of PANI might cause its underutilization that induces a decrease of the specific capacitance [56].

Besides, the EIS measurements of the cellulose/PANI and cellulose/ $\mathrm{GO}_{3.5} / \mathrm{PANI}$ electrodes were examined to gain more insight into the interfacial transfer kinetics of electrolyte ions. As presented in Figure S2d, the Nyquist plots show a single semicircle at high-frequency region with the $x$ intercept of 1.6 and $2.4 \Omega$ for cellulose/PANI and cellulose/ $\mathrm{GO}_{3.5} / \mathrm{PANI}$, respectively, reflecting small equivalent series resistance. The diameter of the semicircles corresponding to the charge transfer resistance is obtained by a fitting circuit, in which much smaller $R_{\mathrm{ct}}$ is found for the cellulose/GO $\mathrm{GO}_{3.5} / \mathrm{PANI}(3.1 \Omega)$ than that of the cellulose/PANI (12.3 $\Omega$ ), implying a much lower charge-transfer resistance. The result is consistent with the improved conductivity of the cellulose/GO $\mathrm{GO}_{3.5} / \mathrm{PANI}$ compared to that of the cellulose/PANI electrode. Figure $6 \mathrm{f}$ shows the electrochemical stability of the cellulose/GO ${ }_{3.5} / \mathrm{PANI}$ electrode during continuous charging and discharging at a constant current density of $15 \mathrm{~mA} / \mathrm{cm}^{2}$. The specific capacitance can preserve $83 \%$ after 1000 charge-discharge cycles. The Coulombic efficiency of $\sim 100 \%$ over 1000 cycles is indicative of outstanding electrochemical reversibility. The proper degradation of capacitance is likely attributed to the structural deterioration of PANI and volumetric changes from expansion and contraction of the electrode, which is still a tough problem for PANI-based supercapacitors [57]. What is more, the cellulose/GO $3.5 / \mathrm{PANI}$ electrode has shown comparability or even superiority in performance when compared with other reported composite materials. Some of the details on enhancements in the areal specific capacitance and the cyclic stability are summarized in Table S1.

\subsection{Electrochemical Performanc of the Fabricated All-Solid-State Supercapacitors}

To evaluate the potential practical application, we assembled all-solid-state supercapacitors with a symmetrical sandwich structure based on cellulose/GO $\mathrm{G}_{3.5} / \mathrm{PANI}$ composite electrodes using $\mathrm{PVA} / \mathrm{H}_{2} \mathrm{SO}_{4}$ gel as the electrolyte. Typical CV profiles of a single device in the range -0.2 to $0.8 \mathrm{~V}$ at different scan rates are shown in Figure 7a. The asymmetric triangular shape of GCD curves also indicates the pseudo-capacitive properties of the cellulose/ $\mathrm{GO}_{3.5} / \mathrm{PANI}$ electrode, as shown in Figure $7 \mathrm{~b}$. The areal capacitances calculated from GCD curves drop from 1858.7 to $909.4 \mathrm{mF} / \mathrm{cm}^{2}$ as the current density increases from 1.0 to $8.0 \mathrm{~mA} / \mathrm{cm}^{2}$ (Figure 7c). Since the thickness of the device 
is of $\sim 0.1 \mathrm{~cm}$, the maximum volumetric capacitance is determined to be $18.5 \mathrm{~F} / \mathrm{cm}^{3}$ at $10.0 \mathrm{~mA} / \mathrm{cm}^{3}$. The maximum capacitive performance of our device is substantially higher than that of previously reported supercapacitors based on the $\mathrm{CNF} / \mathrm{rGO} / \mathrm{CNT}$ hybrid aerogel electrode $\left(216 \mathrm{mF} / \mathrm{cm}^{2}\right.$ at $0.5 \mathrm{~A} / \mathrm{g})$ [58], $\mathrm{PANI} / \mathrm{Ag} / \mathrm{CNF}$ aerogel $\left(176 \mathrm{mF} / \mathrm{cm}^{2}\right.$ at the scan rate of $\left.10 \mathrm{mV} / \mathrm{s}\right)$ [59], polypyrrole/rGO/BC flexible electrode $\left(790 \mathrm{mF} / \mathrm{cm}^{2}\right.$ at $\left.1.0 \mathrm{~mA} / \mathrm{cm}^{2}\right)$ [60], and PANI/BC/graphene paper $\left(1.93 \mathrm{~F} / \mathrm{cm}^{2}\right.$ at $0.25 \mathrm{~mA} / \mathrm{cm}^{2}$ ) [61]. The high areal capacitance and rate capability are ascribed to the high compatibility of the cellulose-based electrode with gel electrolyte, which endows effective ion diffusion pathways to the interior of the PANI coating [31].
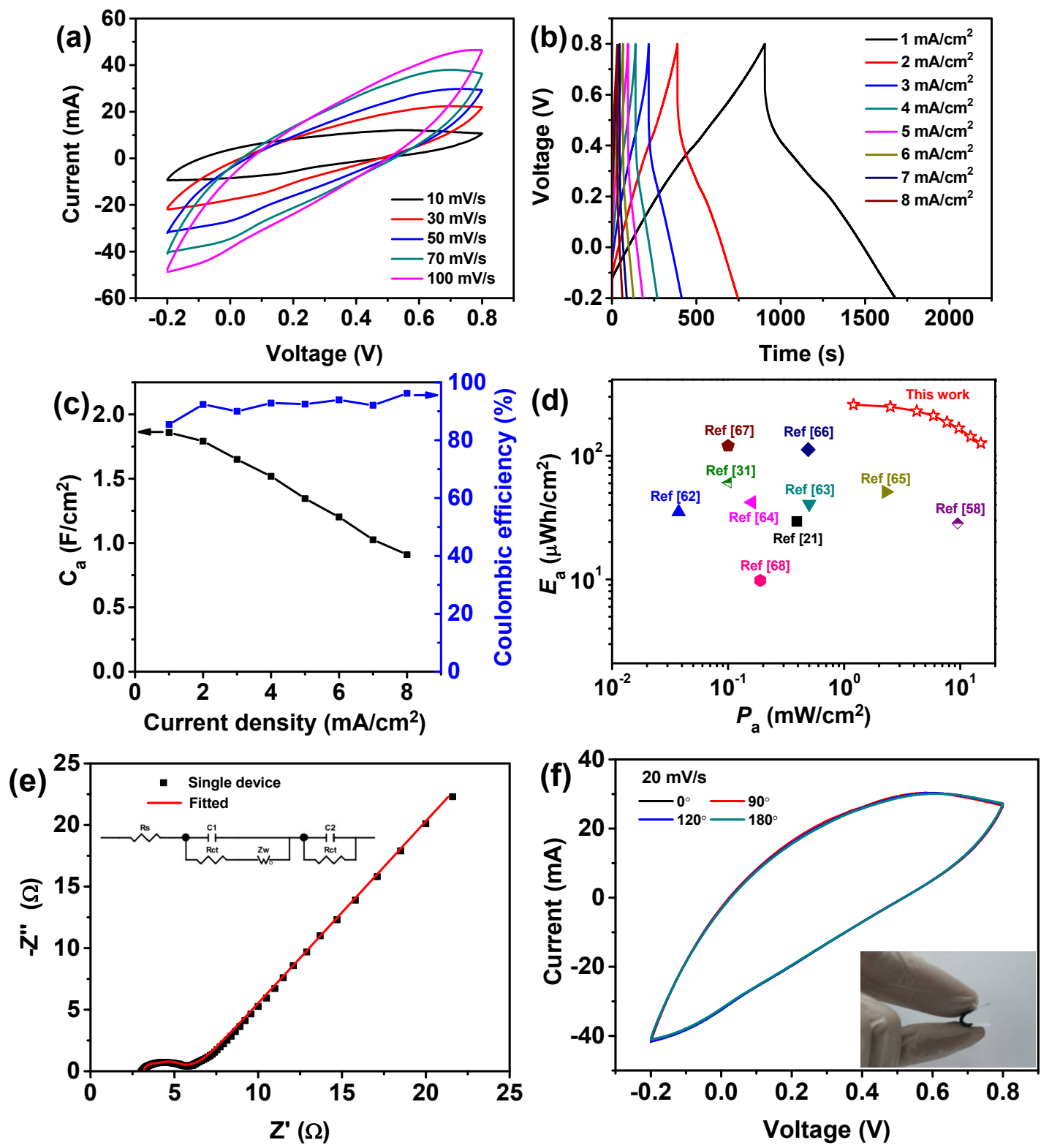

Figure 7. (a) Typical CV curves of the assembled supercapacitor at different scan rates. (b) GCD curves of the single device at different current densities. (c) The areal capacitance varied with different current densities. (d) Ragone plots and comparisons with those of the reported solid-state supercapacitors. (e) Nyquist plot of the supercapacitor with an equivalent circuit in the inset. (f) CV profiles of the device at flat and at $90^{\circ}, 120^{\circ}$, and $180^{\circ}$ bending deformations.

Moreover, according to Equations (4) and (5), the energy and power density of the assembled supercapacitor is obtained from the GCD curves and is manifested in the Ragone diagram (Figure 7d). 
The device achieves a maximum energy density of $258.2 \mu \mathrm{Wh} / \mathrm{cm}^{2}$ at a power density of $1201.4 \mu \mathrm{W} / \mathrm{cm}^{2}$, and still can store an energy density of $126.3 \mu \mathrm{Wh} / \mathrm{cm}^{2}$ at the power density of $15.1 \mathrm{~mW} / \mathrm{cm}^{2}$ as the current density increased from 1.0 to $8.0 \mathrm{~mA} / \mathrm{cm}^{2}$. The corresponding areal energy and power density values are much higher than the recently reported supercapacitors based on PANI/CNT paper $\left(29.4 \mu \mathrm{Wh} / \mathrm{cm}^{2}\right.$ at $\left.391 \mu \mathrm{W} / \mathrm{cm}^{2}\right)$ [21], CNFs/rGO/PPy $\left(60.5 \mu \mathrm{Wh} / \mathrm{cm}^{2}\right.$ at $\left.0.1 \mathrm{MW} / \mathrm{cm}^{2}\right)$ [31], CNF/RGO/CNT aerogel $\left(28.4 \mu \mathrm{Wh} / \mathrm{cm}^{2}\right.$ at $\left.9.5 \mathrm{MW} / \mathrm{cm}^{2}\right)$ [58], $\mathrm{RGO} / \mathrm{MnO}_{2}$ paper $\left(35.1 \mu \mathrm{Wh} / \mathrm{cm}^{2}\right.$ at $\left.37.5 \mu \mathrm{W} / \mathrm{cm}^{2}\right)$ [62], $\mathrm{rGO} / \mathrm{PANI}-\mathrm{PSS}$ papers $\left(40.7 \mu \mathrm{Wh} / \mathrm{cm}^{2}\right.$ at $\left.500 \mu \mathrm{W} / \mathrm{cm}^{2}\right)$ [63], $\mathrm{PANI} / \mathrm{PVA}-\mathrm{H}_{2} \mathrm{SO}_{4}$ chemical hydrogel film $\left(42 \mu \mathrm{Wh} / \mathrm{cm}^{2}\right.$ at $\left.160 \mu \mathrm{W} / \mathrm{cm}^{2}\right)$ [64], CNT@PANI film $\left(50.98 \mu \mathrm{Wh} / \mathrm{cm}^{2}\right.$ at $\left.2294 \mu \mathrm{W} / \mathrm{cm}^{2}\right)$ [65], CNT/activated carbon fiber felt $\left(112 \mu \mathrm{Wh} / \mathrm{cm}^{2}\right.$ at $\left.490 \mu \mathrm{W} / \mathrm{cm}^{2}\right)$ [66], PANI/GN/BC paper $\left(120 \mu \mathrm{Wh} / \mathrm{cm}^{2}\right.$ at $\left.100 \mu \mathrm{W} / \mathrm{cm}^{2}\right)$ [67], and carbon microfiber/MWCNT $\left(9.8 \mu W h / \mathrm{cm}^{2}\right.$ at $\left.189.4 \mu W / \mathrm{cm}^{2}\right)$ [68]. EIS analysis of the single device (Figure 7e) indicates that the $R_{\mathrm{s}}$ and $R_{\mathrm{ct}}$ are of 3.2 and $1.9 \Omega$, respectively. The electrochemical properties of the fabricated supercapacitor were also tested at various bending angles (from $0^{\circ}$ to $180^{\circ}$, Figure $7 \mathrm{f}$ ). The overlapped CV curves demonstrate the device has excellent electrochemical behavior under various bending deformations. The relatively small $R_{\mathrm{s}}$ and $R_{\mathrm{ct}}$ and excellent flexibility indicate its appropriate configuration design, and some larger area supercapacitors could be fabricated for integrating into wearable electronics.

To access the real-life applications of the as-assembled supercapacitor, more devices can be connected in series and parallel connections. For instance, Figure 8a shows the CV curves of two devices in series and parallel connections along with the comparison of the single device. The observations indicate an extended the operating window of two devices in series and an enlarged capacity by parallel under the same current density. Moreover, three times the operating voltage was obtained by three devices connected in series, which can drive a red LED bulb to light up for almost $4 \mathrm{~min}$, as manifested in Figure 8b,c. All of these results demonstrate that our flexible supercapacitors based on the cellulose/ $\mathrm{GO}_{3.5} / \mathrm{PANI}$ electrode are promising in flexible and lightweight electronics.
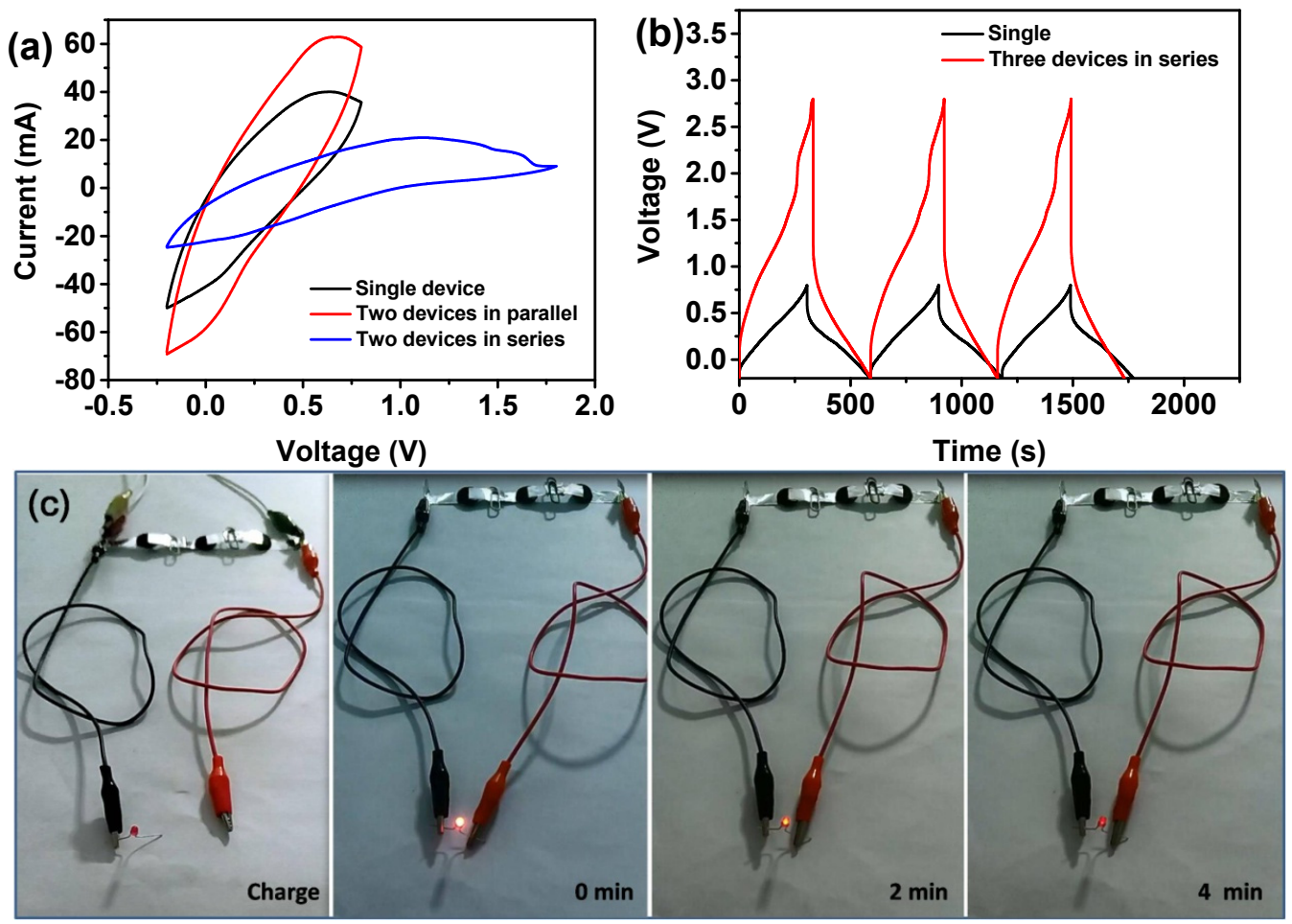

Figure 8. (a) CV profiles of the single device, two devices in series, and two devices in parallel connection at a scan rate of $50 \mathrm{mV} / \mathrm{s}$. (b) GCD profiles of the single device and three devices in series at a current density of $2 \mathrm{~mA} / \mathrm{cm}^{2}$. (c) Optical pictures of three devices in series connection to light a LED lamp for $4 \mathrm{~min}$. 


\section{Conclusions}

Free-standing cellulose/GO/PANI composite aerogels can be delicately synthesized by in-situ polymerization of aniline in the cellulose/GO three-dimensional frameworks. With the high conductivity, the cellulose/GO/PANI aerogels can serve as electrode materials in the absence of any other binders, and retain high flexibility that can be bent to a large degree. Excellent electrochemical performances are achieved for the cellulose/GO $\mathrm{GO}_{3.5} / \mathrm{PANI}$ electrode, which produced a maximum areal specific capacitance of $1218 \mathrm{mF} / \mathrm{cm}^{2}$ at a current density of $1.0 \mathrm{~mA} / \mathrm{cm}^{2}$ and maintained good cycling stability with capacitance retention of $83 \%$ after 1000 charge-discharge cycles. Moreover, benefiting from the optimized weight ratio of GO and PANI, the special three-dimensional porous structure, and the synergistic effect between components, the assembled supercapacitor based on the cellulose/GO $3.5 / \mathrm{PANI}$ electrode can deliver an outstanding energy density as high as $258.2 \mu \mathrm{Wh} / \mathrm{cm}^{2}$ at a power density of $1201.4 \mu \mathrm{W} / \mathrm{cm}^{2}$, which is superior to that of the aerogel-based flexible supercapacitors reported previously. Therefore, this study provides a promising and efficient way for the preparation of ideal electrode materials for high-performance flexible energy storage devices.

Supplementary Materials: The following are available online at http:/www.mdpi.com/2079-4991/10/8/1546/s1, Figure S1: The cellulose/GO3.5/PANI film was folded and used as a wire to light up a red LED. Figure S2: (a) CV curves of the cellulose/GO $\mathrm{GO}_{1.0} / \mathrm{PANI}$, cellulose/ $\mathrm{GO}_{2.0} / \mathrm{PANI}$, cellulose/GO $\mathrm{GO}_{3.5} / \mathrm{PANI}$, and cellulose/GO $5.0 / \mathrm{PANI}$ samples at $10 \mathrm{mV} / \mathrm{s}$. (b) CV curves of cellulose/PANI sample. (c) GCD curves of cellulose/PANI sample. (d) Nyquist plot of the cellulose/PANI and cellulose/GO/PANI with an equivalent circuit in the inset. Figure S3: (a) CV curves of the cellulose $/ \mathrm{GO}_{3.5} / \mathrm{PANI}{ }_{0.5 \mathrm{M}}$, cellulose $/ \mathrm{GO}_{3.5} / \mathrm{PANI}_{0.75 \mathrm{M}}$, cellulose $/ \mathrm{GO}_{3.5} / \mathrm{PANI}_{1.0 \mathrm{M}}$ (namely cellulose $/ \mathrm{GO}_{3.5} / \mathrm{PANI}$ sample in the main text), and cellulose/GO $\mathrm{GO}_{3.5} / \mathrm{PANI}_{1.25 \mathrm{M}}$ samples at $10 \mathrm{mV} / \mathrm{s}$. (d) GCD curves of the cellulose/ $\mathrm{GO}_{3.5} / \mathrm{PANI}_{0.5 \mathrm{M}}$, cellulose $/ \mathrm{GO}_{3.5} / \mathrm{PANI}_{0.75 \mathrm{M}}$, cellulose/GO $\mathrm{GO}_{3.5} / \mathrm{PANI} \mathrm{AN}_{1.0 \mathrm{M}}$, and cellulose/GO $\mathrm{GO}_{3.5} / \mathrm{PANI}_{1.25 \mathrm{M}}$ samples. Table S1: Comparison of the electrochemical performance of various electrodes based on conducting fillers/ cellulose composites.

Author Contributions: Conceptualization, Y.L. and Z.X.; methodology, Z.X., Q.G., and X.L.; software, Q.G. and Y.Y.; validation, Y.L., Z.X., C.C., and C.Q.; formal analysis, Z.X., Q.G., and X.L.; investigation, Y.L., Z.X., Q.G., and X.L.; resources, Z.X.; data curation, Y.L., Z.X., C.C., and C.Q.; writing-original draft preparation, Y.L. and Z.X.; writing-review and editing, Y.L.; visualization, Y.L. and Z.X.; supervision, Y.L.; project administration, Y.L.; funding acquisition, Y.L. and Q.G. All authors have read and agreed to the published version of the manuscript.

Funding: This research was funded by Natural Science Foundation of the Jiangsu Higher Education Institutions of China, grant number 18 KJB150021, and Postgraduate Research and Practice Innovation Program of Jiangsu Province, grant number SJCX19_0296.

Acknowledgments: The authors gratefully acknowledge the facilities support from the Priority Academic Program Development of Jiangsu Higher Education Institutions (PAPD) and Advanced Analysis and Testing Center of Nanjing Forestry University.

Conflicts of Interest: The authors declare no conflict of interest.

\section{References}

1. Raza, W.; Ali, F.; Raza, N.; Luo, Y.; Kim, K.-H.; Yang, J.; Kumar, S.; Mehmood, A.; Kwon, E.E. Recent advancements in supercapacitor technology. Nano Energy 2018, 52, 441-473. [CrossRef]

2. Shao, Y.; El-Kady, M.F.; Sun, J.; Li, Y.; Zhang, Q.; Zhu, M.; Wang, H.; Dunn, B.; Kaner, R.B. Design and mechanisms of asymmetric supercapacitors. Chem. Rev. 2018, 118, 9233-9280. [CrossRef] [PubMed]

3. Lu, X.; Yu, M.; Wang, G.; Tong, Y.; Li, Y. Flexible solid-state supercapacitors: Design, fabrication and applications. Energy Environ. Sci. 2014, 7, 2160-2181. [CrossRef]

4. Dubal, D.P.; Chodankar, N.R.; Kim, D.-H.; Gomez-Romero, P. Towards flexible solid-state supercapacitors for smart and wearable electronics. Chem. Soc. Rev. 2018, 47, 2065-2129. [CrossRef] [PubMed]

5. Weng, Z.; Su, Y.; Wang, D.-W.; Li, F.; Du, J.; Cheng, H.-M. Graphene-cellulose paper flexible supercapacitors. Adv. Energy Mater. 2011, 1, 917-922. [CrossRef]

6. Ge, D.; Yang, L.; Fan, L.; Zhang, C.; Xiao, X.; Gogotsi, Y.; Yang, S. Foldable supercapacitors from triple networks of macroporous cellulose fibers, single-walled carbon nanotubes and polyaniline nanoribbons. Nano Energy 2015, 11, 568-578. [CrossRef]

7. Hou, M.; Xu, M.; Hu, Y.; Li, B. Nanocellulose incorporated graphene/polypyrrole film with a sandwich-like architecture for preparing flexible supercapacitor electrodes. Electrochim. Acta 2019, 313, 245-254. [CrossRef] 
8. Pérez-Madrigal, M.M.; Edo, M.G.; Alemán, C. Powering the future: Application of cellulose-based materials for supercapacitors. Green Chem. 2016, 18, 5930-5956. [CrossRef]

9. Dong, L.; Xu, C.; Li, Y.; Pan, Z.; Liang, G.; Zhou, E.; Kang, F.; Yang, Q.-H. Breathable and wearable energy storage based on highly flexible paper electrodes. Adv. Mater. 2016, 28, 9313-9319. [CrossRef]

10. Wang, Z.; Tammela, P.; Strømme, M.; Nyholm, L. Cellulose-based supercapacitors: Material and performance considerations. Adv. Energy Mater. 2017, 7, 1700130. [CrossRef]

11. Zhao, D.; Zhu, Y.; Cheng, W.; Chen, W.; Wu, Y.; Yu, H. Cellulose-based flexible functional materials for emerging intelligent electronics. Adv. Mater. 2020, 32, 2000619. [CrossRef] [PubMed]

12. Snook, G.A.; Kao, P.; Best, A.S. Conducting-polymer-based supercapacitor devices and electrodes. J. Power Sources 2011, 196, 1-12. [CrossRef]

13. Zhang, L.L.; Zhao, X.S. Carbon-based materials as supercapacitor electrodes. Chem. Soc. Rev. 2009, 38, $2520-2531$. [CrossRef] [PubMed]

14. Baptista, A.C.; Ropio, I.; Romba, B.; Nobre, J.P.; Henriques, C.; Silva, J.C.; Martins, J.I.; Borges, J.P.; Ferreira, I. Cellulose-based electrospun fibers functionalized with polypyrrole and polyaniline for fully organic batteries. J. Mater. Chem. A 2018, 6, 256-265. [CrossRef]

15. Zheng, W.; Lv, R.; Na, B.; Liu, H.; Jin, T.; Yuan, D. Nanocellulose-mediated hybrid polyaniline electrodes for high performance flexible supercapacitors. J. Mater. Chem. A 2017, 5, 12969-12976. [CrossRef]

16. Yuan, L.; Yao, B.; Hu, B.; Huo, K.; Chen, W.; Zhou, J. Polypyrrole-coated paper for flexible solid-state energy storage. Energy Environ. Sci. 2013, 6, 470-476. [CrossRef]

17. Lyu, S.; Chang, H.; Fu, F.; Hu, L.; Huang, J.; Wang, S. Cellulose-coupled graphene/polypyrrole composite electrodes containing conducting networks built by carbon fibers as wearable supercapacitors with excellent foldability and tailorability. J. Power Sources 2016, 327, 438-446. [CrossRef]

18. Liu, R.; Ma, L.; Huang, S.; Mei, J.; Xu, J.; Yuan, G. A flexible polyaniline/graphene/bacterial cellulose supercapacitor electrode. New J. Chem. 2017, 41, 857-864. [CrossRef]

19. Luo, H.; Dong, J.; Zhang, Y.; Li, G.; Guo, R.; Zuo, G.; Ye, M.; Wang, Z.; Yang, Z.; Wan, Y. Constructing 3D bacterial cellulose/graphene/polyaniline nanocomposites by novel layer-by-layer in-situ culture toward mechanically robust and highly flexible freestanding electrodes for supercapacitors. Chem. Eng. J. 2018, 334, 1148-1158. [CrossRef]

20. Bai, Y.; Liu, R.; Li, E.; Li, X.; Liu, Y.; Yuan, G. Graphene/carbon nanotube/bacterial cellulose assisted supporting for polypyrrole towards flexible supercapacitor applications. J. Alloys Compd. 2019, 777, 524-530. [CrossRef]

21. Dong, L.; Liang, G.; Xu, C.; Ren, D.; Wang, J.; Pan, Z.-Z.; Li, B.; Kang, F.; Yang, Q.-H. Stacking up layers of polyaniline/carbon nanotube networks inside papers as highly flexible electrodes with large areal capacitance and superior rate capability. J. Mater. Chem. A 2017, 5, 19934-19942. [CrossRef]

22. Xu, Y.; Ren, B.; Wang, S.; Zhang, L.; Liu, Z. Carbon aerogel-based supercapacitors modified by hummers oxidation method. J. Colloid Interface Sci. 2018, 527, 25-32. [CrossRef] [PubMed]

23. Yang, Q.; Yang, J.; Gao, Z.; Li, B.; Xiong, C. Carbonized cellulose nanofibril/graphene oxide composite aerogels for high-performance supercapacitors. ACS Appl. Energy Mater. 2020, 3, 1145-1151. [CrossRef]

24. Korkmaz, S.; Kariper, İ.A. Graphene and graphene oxide based aerogels: Synthesis, characteristics and supercapacitor applications. J. Energy Storage 2020, 27, 101038. [CrossRef]

25. Wei, X.; Huang, T.; Yang, J.-H.; Zhang, N.; Wang, Y.; Zhou, Z.-W. Green synthesis of hybrid graphene oxide/microcrystalline cellulose aerogels and their use as superabsorbents. J. Hazard. Mater. 2017, 335, $28-38$. [CrossRef]

26. Li, L.; Lu, F.; Wang, C.; Zhang, F.; Liang, W.; Kuga, S.; Dong, Z.; Zhao, Y.; Huang, Y.; Wu, M. Flexible double-cross-linked cellulose-based hydrogel and aerogel membrane for supercapacitor separator. J. Mater. Chem. A 2018, 6, 24468-24478. [CrossRef]

27. Niu, Q.; Guo, Y.; Gao, K.; Shao, Z. Polypyrrole/cellulose nanofiber aerogel as a supercapacitor electrode material. RSC Adv. 2016, 6, 109143-109149. [CrossRef]

28. Pinto, S.C.; Gonçalves, G.; Sandoval, S.; López-Periago, A.M.; Borras, A.; Domingo, C.; Tobias, G.; Duarte, I.; Vicente, R.; Marques, P.A.A.P. Bacterial cellulose/graphene oxide aerogels with enhanced dimensional and thermal stability. Carbohydr. Polym. 2020, 230, 115598. [CrossRef]

29. Wei, X.; Xue, F.; Qi, X.-D.; Yang, J.-H.; Zhou, Z.-W.; Yuan, Y.-P.; Wang, Y. Photo-and electro-responsive phase change materials based on highly anisotropic microcrystalline cellulose/graphene nanoplatelet structure. Appl. Energy 2019, 236, 70-80. [CrossRef] 
30. Wang, D.-C.; Yu, H.-Y.; Qi, D.; Ramasamy, M.; Yao, J.; Tang, F.; Tam, K.C.; Ni, Q. Supramolecular self-assembly of 3D conductive cellulose nanofiber aerogels for flexible supercapacitors and ultrasensitive sensors. ACS Appl. Mater. Interfaces 2019, 11, 24435-24446. [CrossRef]

31. Zhang, Y.; Shang, Z.; Shen, M.; Chowdhury, S.P.; Ignaszak, A.; Sun, S.; Ni, Y. Cellulose nanofibers/reduced graphene oxide/polypyrrole aerogel electrodes for high-capacitance flexible all-solid-state supercapacitors. ACS Sustainable Chem. Eng. 2019, 7, 11175-11185. [CrossRef]

32. Lyu, S.; Chen, Y.; Zhang, L.; Han, S.; Lu, Y.; Chen, Y.; Yang, N.; Chen, Z.; Wang, S. Nanocellulose supported hierarchical structured polyaniline/nanocarbon nanocomposite electrode via layer-by-layer assembly for green flexible supercapacitors. RSC Adv. 2019, 9, 17824-17834. [CrossRef]

33. Li, Y.; Zhou, M.; Xia, Z.; Gong, Q.; Liu, X.; Yang, Y.; Gao, Q. Facile preparation of polyaniline covalently grafted to isocyanate functionalized reduced graphene oxide nanocomposite for high performance flexible supercapacitors. Colloids Surf. A 2020, 602, 125172. [CrossRef]

34. Qin, B.; Wang, Q.; Zhang, X.; Xie, X.; Jin, L.E.; Cao, Q. One-pot synthesis of interconnected porous carbon derived from coal tar pitch and cellulose for high-performance supercapacitors. Electrochim. Acta 2018, 283, 655-663. [CrossRef]

35. Lu, Y.; Zhang, S.; Yin, J.; Bai, C.; Zhang, J.; Li, Y.; Yang, Y.; Ge, Z.; Zhang, M.; Wei, L.; et al. Mesoporous activated carbon materials with ultrahigh mesopore volume and effective specific surface area for high performance supercapacitors. Carbon 2017, 124, 64-71. [CrossRef]

36. Yu, J.; Xie, F.; Wu, Z.; Huang, T.; Wu, J.; Yan, D.; Huang, C.; Li, L. Flexible metallic fabric supercapacitor based on graphene/polyaniline composites. Electrochim. Acta 2018, 259, 968-974. [CrossRef]

37. Zhou, H.; Han, G.; Xiao, Y.; Chang, Y.; Zhai, H.-J. Facile preparation of polypyrrole/graphene oxide nanocomposites with large areal capacitance using electrochemical codeposition for supercapacitors. J. Power Sources 2014, 263, 259-267. [CrossRef]

38. Zhao, Y.; Alsaid, Y.; Yao, B.; Zhang, Y.; Zhang, B.; Bhuskute, N.; Wu, S.; He, X. Wood-inspired morphologically tunable aligned hydrogel for high-performance flexible all-solid-state supercapacitors. Adv. Funct. Mater. 2020, 30, 1909133. [CrossRef]

39. Zou, Y.; Liu, R.; Zhong, W.; Yang, W. Mechanically robust double-crosslinked network functionalized graphene/polyaniline stiff hydrogels for superior performance supercapacitors. J. Mater. Chem. A 2018, 6, 8568-8578. [CrossRef]

40. Gong, Q.; Li, Y.; Liu, X.; Xia, Z.; Yang, Y. A facile preparation of polyaniline/cellulose hydrogels for all-in-one flexible supercapacitor with remarkable enhanced performance. Carbohydr. Polym. 2020, 245, 116611. [CrossRef]

41. Zhang, J.; Yang, H.; Shen, G.; Cheng, P.; Zhang, J.; Guo, S. Reduction of graphene oxide vial-ascorbic acid. Chem. Commun. 2010, 46, 1112-1114. [CrossRef] [PubMed]

42. Yang, C.; Chen, C.; Pan, Y.; Li, S.; Fei, W.; Li, J.; Li, N.; Li, X.; Zhang, Y.; Li, D. Flexible highly specific capacitance aerogel electrodes based on cellulose nanofibers, carbon nanotubes and polyaniline. Electrochim. Acta 2015, 182, 264-271. [CrossRef]

43. Yang, C.; Li, D. Flexible and foldable supercapacitor electrodes from the porous 3D network of cellulose nanofibers, carbon nanotubes and polyaniline. Mater. Lett. 2015, 155, 78-81. [CrossRef]

44. Ren, F.; Li, Z.; Tan, W.-Z.; Liu, X.-H.; Sun, Z.-F.; Ren, P.-G.; Yan, D.-X. Facile preparation of 3D regenerated cellulose/graphene oxide composite aerogel with high-efficiency adsorption towards methylene blue. J. Colloid Interface Sci. 2018, 532, 58-67. [CrossRef]

45. Du, F.-P.; Cao, N.-N.; Zhang, Y.-F.; Fu, P.; Wu, Y.-G.; Lin, Z.-D.; Shi, R.; Amini, A.; Cheng, C. PEDOT:PSS/ graphene quantum dots films with enhanced thermoelectric properties via strong interfacial interaction and phase separation. Sci. Rep. 2018, 8, 6441. [CrossRef]

46. Ling, Z.; Chen, S.; Zhang, X.; Takabe, K.; Xu, F. Unraveling variations of crystalline cellulose induced by ionic liquid and their effects on enzymatic hydrolysis. Sci. Rep. 2017, 7, 10230. [CrossRef]

47. Li, Y.; Zhang, Q.; Zhao, X.; Yu, P.; Wu, L.; Chen, D. Enhanced electrochemical performance of polyaniline/ sulfonated polyhedral oligosilsesquioxane nanocomposites with porous and ordered hierarchical nanostructure. J. Mater. Chem. 2012, 22, 1884-1892. [CrossRef]

48. Shi, X.; Hu, Y.; Li, M.; Duan, Y.Y.; Wang, Y.; Chen, L.; Zhang, L. Highly specific capacitance materials constructed via in-situ synthesis of polyaniline in a cellulose matrix for supercapacitors. Cellulose 2014, 21, 2337-2347. [CrossRef] 
49. Zou, Y.; Zhang, Z.; Zhong, W.; Yang, W. Hydrothermal direct synthesis of polyaniline, graphene/polyaniline and $\mathrm{N}$-doped graphene/polyaniline hydrogels for high performance flexible supercapacitors. J. Mater. Chem. A 2018, 6, 9245-9256. [CrossRef]

50. Deng, J.; Wang, T.; Guo, J.; Liu, P. Electrochemical capacity fading of polyaniline electrode in supercapacitor: An XPS analysis. Prog. Nat. Sci. 2017, 27, 257-260. [CrossRef]

51. Vallés, C.; Jiménez, P.; Muñoz, E.; Benito, A.M.; Maser, W.K. Simultaneous reduction of graphene oxide and polyaniline: Doping-assisted formation of a solid-state charge-transfer complex. J. Phys. Chem. C 2011, 115, 10468-10474. [CrossRef]

52. Lv, P.; Tang, X.; Zheng, R.; Ma, X.; Yu, K.; Wei, W. Graphene/polyaniline aerogel with superelasticity and high capacitance as highly compression-tolerant supercapacitor electrode. Nanoscale Res. Lett. 2017, 12, 630. [CrossRef] [PubMed]

53. Stankovich, S.; Dikin, D.A.; Piner, R.D.; Kohlhaas, K.A.; Kleinhammes, A.; Jia, Y.; Wu, Y.; Nguyen, S.T.; Ruoff, R.S. Synthesis of graphene-based nanosheets via chemical reduction of exfoliated graphite oxide. Carbon 2007, 45, 1558-1565. [CrossRef]

54. Pan, L.; Yu, G.; Zhai, D.; Lee, H.R.; Zhao, W.; Liu, N.; Wang, H.; Tee, B.C.K.; Shi, Y.; Cui, Y.; et al. Hierarchical nanostructured conducting polymer hydrogel with high electrochemical activity. Proc. Natl. Acad. Sci. USA 2012, 109, 9287-9292. [CrossRef] [PubMed]

55. Li, J.; Yin, M.; Guo, C.; Zhang, H.; Li, T.; Wang, H.; Wei, Y.; Hou, L.; Jia, C. Belt-like $\mathrm{MnO}_{2}$ cathode to enable high energy density and ultra-stable aqueous asymmetric supercapacitor. Surf. Coat. Technol. 2019, 359, 175-182. [CrossRef]

56. Wu, X.; Tang, L.; Zheng, S.; Huang, Y.; Yang, J.; Liu, Z.; Yang, W.; Yang, M. Hierarchical unidirectional graphene aerogel/polyaniline composite for high performance supercapacitors. J. Power Sources 2018, 397, 189-195. [CrossRef]

57. Eftekhari, A.; Li, L.; Yang, Y. Polyaniline supercapacitors. J. Power Sources 2017, 347, 86-107. [CrossRef]

58. Zheng, Q.; Cai, Z.; Ma, Z.; Gong, S. Cellulose nanofibril/reduced graphene oxide/carbon nanotube hybrid aerogels for highly flexible and all-solid-state supercapacitors. ACS Appl. Mater. Interfaces 2015, 7, 3263-3271. [CrossRef]

59. Zhang, X.; Lin, Z.; Chen, B.; Zhang, W.; Sharma, S.; Gu, W.; Deng, Y. Solid-state flexible polyaniline/silver cellulose nanofibrils aerogel supercapacitors. J. Power Sources 2014, 246, 283-289. [CrossRef]

60. Ma, L.; Liu, R.; Niu, H.; Zhao, M.; Huang, Y. Flexible and freestanding electrode based on polypyrrole/ graphene/bacterial cellulose paper for supercapacitor. Compos. Sci. Technol. 2016, 137, 87-93. [CrossRef]

61. Liu, R.; Ma, L.; Huang, S.; Mei, J.; Xu, J.; Yuan, G. Large areal mass, flexible and freestanding polyaniline/bacterial cellulose/graphene film for high-performance supercapacitors. RSC Adv. 2016, 6, 107426-107432. [CrossRef]

62. Afriyanti, S.; Ce Yao, F.; Xu, W.; Pooi See, L. Large areal mass, flexible and free-standing reduced graphene oxide/manganese dioxide paper for asymmetric supercapacitor device. Adv. Mater. 2013, 25, 2809-2815.

63. Chao, Y.; Zhang, L.; Hu, N.; Zhi, Y.; Hao, W.; Xu, Z.J.; Wang, Y.; Zhang, Y. Densely-packed graphene/conducting polymer nanoparticle papers for high-volumetric-performance flexible all-solid-state supercapacitors. Appl. Surface Sci. 2016, 379, 206-212.

64. Wang, K.; Zhang, X.; Li, C.; Sun, X.; Meng, Q.; Ma, Y.; Wei, Z. Chemically crosslinked hydrogel film leads to integrated flexible supercapacitors with superior performance. Adv. Mater. 2016, 27, 7451-7457. [CrossRef]

65. Yu, J.; Lu, W.; Pei, S.; Gong, K.; Wang, L.; Meng, L.; Huang, Y.; Smith, J.P.; Booksh, K.S.; Li, Q.; et al. Omnidirectionally stretchable high-performance supercapacitor based on isotropic buckled carbon nanotube films. Acs Nano 2016, 10, 5204-5211. [CrossRef]

66. Dong, L.; Xu, C.; Yang, Q.; Fang, J.; Li, Y.; Kang, F. High-performance compressible supercapacitors based on functionally synergic multiscale carbon composite textiles. J. Mater. Chem. A 2015, 3, 4729-4737. [CrossRef]

67. Rong, L.; Ma, L.; Shu, H.; Jia, M.; Xu, J.; Yuan, G. Polyaniline/graphene/bacterial cellulose flexible electrodes for supercapacitor. New J. Chem. 2016, 41, 857-864.

68. Le, V.T.; Kim, H.; Ghosh, A.; Kim, J.; Chang, J.; Vu, Q.A.; Pham, D.T.; Lee, J.-H.; Kim, S.-W.; Lee, Y.H. Coaxial fiber supercapacitor using all-carbon material electrodes. Acs Nano 2013, 7, 5940-5947. [CrossRef]

(C) 2020 by the authors. Licensee MDPI, Basel, Switzerland. This article is an open access article distributed under the terms and conditions of the Creative Commons Attribution (CC BY) license (http://creativecommons.org/licenses/by/4.0/). 